\title{
Modelling of wave propagation and attenuation in the Osaka sedimentary basin, western Japan, during the 2013 Awaji Island earthquake
}

\section{$\operatorname{AUTHOR}(\mathrm{S})$ :}

Asano, Kimiyuki; Sekiguchi, Haruko; Iwata, Tomotaka; Yoshimi, Masayuki; Hayashida, Takumi; Saomoto, Hidetaka; Horikawa, Haruo

\section{CITATION:}

Asano, Kimiyuki ... [et al]. Modelling of wave propagation and attenuation in the Osaka sedimentary basin, western Japan, during the 2013 Awaji Island earthquake. Geophysical Journal International 2016, 204(3): 1678-1694

\section{ISSUE DATE:}

2016-02-01

\section{URL:}

http://hdl.handle.net/2433/226323

\section{RIGHT:}

This article has been accepted for publication in 'Geophysical Journal International' (c) The Authors 2016. Published by Oxford University Press on behalf of the Royal Astronomical Society. All rights reserved. 


\title{
Modelling of wave propagation and attenuation in the Osaka sedimentary basin, western Japan, during the 2013 Awaji Island earthquake
}

\author{
Kimiyuki Asano, ${ }^{1}$ Haruko Sekiguchi, ${ }^{1}$ Tomotaka Iwata, ${ }^{1}$ Masayuki Yoshimi, ${ }^{2}$ \\ Takumi Hayashida, ${ }^{3}$ Hidetaka Saomoto ${ }^{2}$ and Haruo Horikawa ${ }^{2}$ \\ ${ }^{1}$ Disaster Prevention Research Institute, Kyoto University, Uji, Kyoto, Japan.E-mail: k-asano@egmdpri01.dpri.kyoto-u.ac.jp \\ ${ }^{2}$ Institute of Earthquake and Volcano Geology, National Institute of Advanced Industrial Science and Technology, Tsukuba, Ibaraki, Japan \\ ${ }^{3}$ International Institute of Seismology and Earthquake Engineering, Building Research Institute, Tsukuba, Ibaraki, Japan
}

Accepted 2015 December 21. Received 2015 November 23; in original form 2014 December 25

\begin{abstract}
SUMMAR Y
On 2013 April 13, an inland earthquake of $M_{\mathrm{w}} 5.8$ occurred in Awaji Island, which forms the western boundary of the Osaka sedimentary basin in western Japan. The strong ground motion data were collected from more than 100 stations within the basin and it was found that in the Osaka Plain, the pseudo velocity response spectra at a period of around $6.5 \mathrm{~s}$ were significantly larger than at other stations of similar epicentral distance outside the basin. The ground motion lasted longer than $3 \mathrm{~min}$ in the Osaka Plain where its bedrock depth spatially varies from approximately 1 to $2 \mathrm{~km}$. We modelled long-period (higher than $2 \mathrm{~s}$ ) ground motions excited by this earthquake, using the finite difference method assuming a point source, to validate the present velocity structure model and to obtain better constraint of the attenuation factor of the sedimentary part of the basin. The effect of attenuation in the simulation was included in the form of $Q(f)=Q_{0}\left(f / f_{0}\right)$, where $Q_{0}$ at a reference frequency $f_{0}$ was given by a function of the $S$-wave velocity, $Q_{0}=\alpha V_{\mathrm{S}}$. We searched for appropriate $Q_{0}$ values by changing $\alpha$ for a fixed value of $f_{0}=0.2 \mathrm{~Hz}$. It was found that values of $\alpha$ from 0.2 to 0.5 fitted the observations reasonably well, but that the value of $\alpha=0.3$ performed best. Good agreement between the observed and simulated velocity waveforms was obtained for most stations within the Osaka Basin in terms of both amplitude and ground motion duration. However, underestimation of the pseudo velocity response spectra in the period range of 5-7 s was recognized in the central part of the Osaka Plain, which was caused by the inadequate modelling of later phases or wave packets in this period range observed approximately $2 \mathrm{~min}$ after the direct $S$-wave arrival. We analysed this observed later phase and concluded that it was a Love wave originating from the direction of the east coast of Awaji Island.
\end{abstract}

Key words: Earthquake ground motions; Seismic attenuation; Site effects; Computational seismology; Wave propagation.

\section{INTRODUCTION}

The Osaka Basin in western Japan is one of the most studied sedimentary basins in the world. It is a Tertiary sedimentary basin surrounded by mountain ranges of Cretaceous and pre-Tertiary sedimentary rocks. Sporadic Oligocene and Miocene sediments and Late Pleistocene terrace deposits are exposed on the hills and the Plio-Pleistocene Osaka Group is present under the alluvial plains (e.g. Nakagawa et al. 1996; Itihara et al. 1997; Itoh et al. 2000). It has an elliptical shape with a long axis of about $90 \mathrm{~km}$ and a short axis of about $40 \mathrm{~km}$. The boundary between the mountains and sedimentary basin is formed by a number of active faults: the Rokko-
Awaji fault system forms the northwest-to-western boundary, the Arima-Takatsuki Tectonic Line forms the northern boundary, the Ikoma and Kongo faults form the eastern boundary and the Median Tectonic Line forms the southern boundary. The Osaka Basin is subdivided geographically into marine and land areas: the former is a shallow inland sea called the Osaka Bay, and the latter comprises the lowlands between the bay and the Uemachi Fault, which in this paper is referred to as the Osaka Plain (see Fig. 1). The maximum thickness of the sediments beneath the Osaka Bay and Osaka Plain are about 3 and $2 \mathrm{~km}$, respectively.

The configuration of such a sedimentary basin amplifies ground motions inside the basin and generates basin-induced surface waves, 

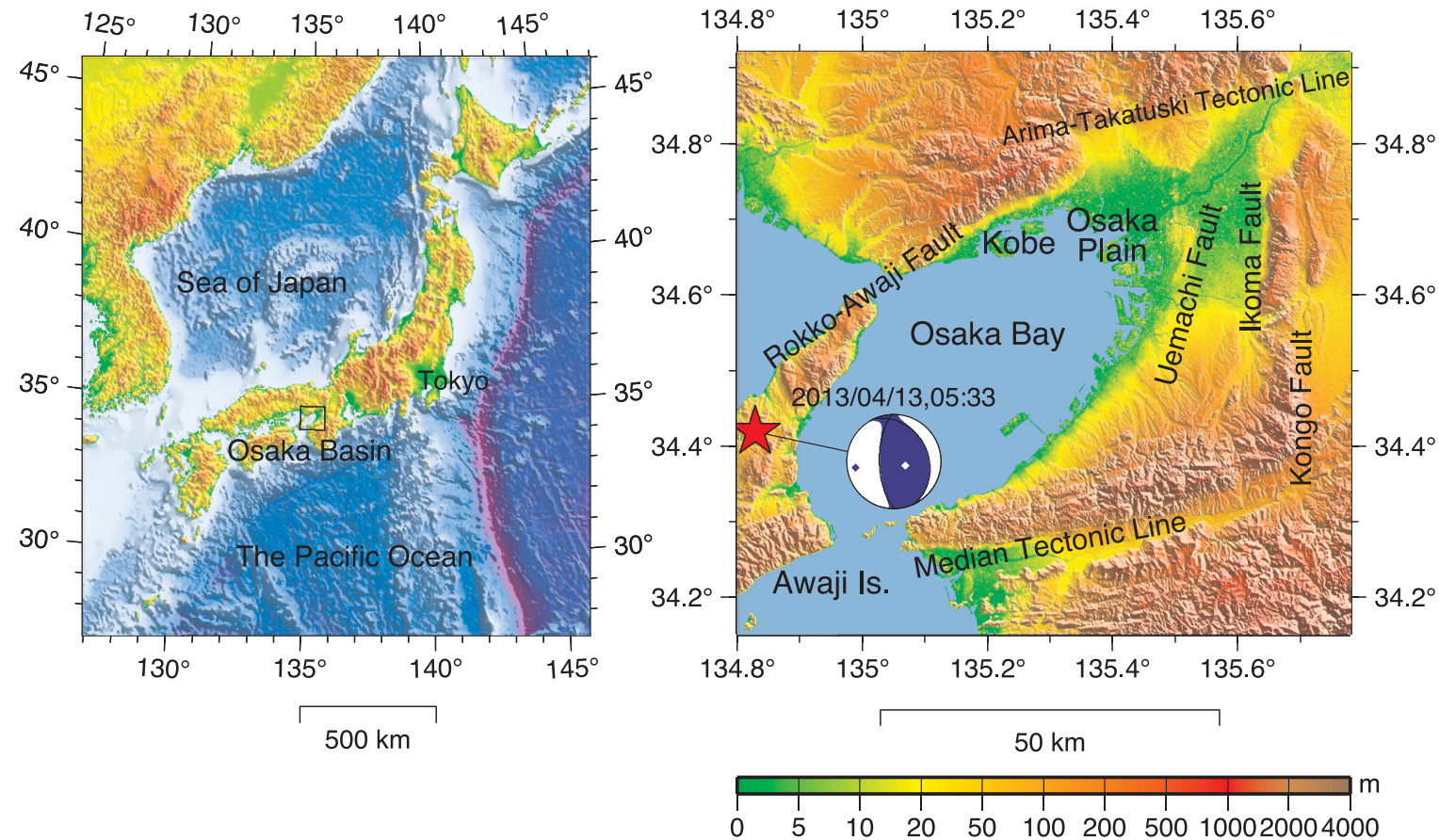

Figure 1. Location of study area. Solid star denotes the epicentre of the 2013 Awaji Island earthquake determined by the JMA. The moment tensor solution of the main shock determined by F-net (NIED) is also shown. Global relief data ETOPO2v2 (U.S. Department of Commerce, National Oceanic and Atmospheric Administration, National Geophysical Data Center 2006) were used to plot the land topography and sea-floor bathymetry in the left-hand panel, and SRTM 90-m Digital Elevation Data (Jarvis et al. 2008) were used to plot the land topography in the right-hand panel.

and many observational and numerical studies have been performed on such basins around the world (e.g. Bard \& Bouchon 1980a,b; Horike 1988; Kawase \& Aki 1989; Frankel 1993; Hatayama et al. 1995; Graves et al. 1998; Pitarka et al. 1998; Joyner 2000; Koketsu $\&$ Kikuchi 2000). For the simulation and prediction of ground motion in a sedimentary basin, it is essential to develop a reliable velocity structure model for the target area. Therefore, detailed 3-D velocity structure models of the Osaka Basin have been developed and subsequently improved based on various types of geophysical and geological explorations, ground motion observations in and around the basin and numerical simulations of wave propagation (e.g. Kagawa et al. 1993, 2004b; Miyakoshi et al. 1997, 1999; Horikawa et al. 2003; Iwata et al. 2008; Iwaki \& Iwata 2011).

Sekiguchi et al. (2013) developed a new 3-D velocity structure model of the Osaka Basin for strong motion prediction of a hypothetical earthquake in the Uemachi active fault system. They constructed their model (hereafter, called the UMC2013 model) considering both geophysical and geological information by adding newly obtained data from reflection surveys, microtremor surveys and receiver function analysis. The validation of how existing 3-D velocity structure models explain observed waveforms, based on ground motion simulations, are important for improving the reliability and uncertainty of ground motion predictions and such studies have been conducted for many sedimentary basins around the world (e.g. Aagaard et al. 2008; Aoi et al. 2008; Ma et al. 2008; Bielak et al. 2010; Iwaki \& Iwata 2010; Dhakal \& Yamanaka 2013; Maufroy et al. 2015).

At 05:33 JST (Japan Standard Time; JST $=$ UTC + 9) on 2013 April 13, an $M_{\mathrm{w}} 5.8$ inland crustal earthquake occurred on Awaji Island. Its hypocentre location determined by the Japan Meteorological Agency (JMA) was $34.4188^{\circ} \mathrm{N}, 134.8290^{\circ} \mathrm{E}$ at a depth of $14.85 \mathrm{~km}$ (Fig. 1). The hypocentre was adjacent to the southwestern boundary of the aftershock area of the 1995 Kobe earthquake $\left(M_{\mathrm{w}}\right.$ 6.8 ), and it marked the strongest event in that area since that time. This event was a reverse faulting earthquake due to east-west compression, whereas the 1995 Kobe earthquake was a strike-slip event. According to the relocated aftershock distributions (Matsuzawa et al. 2013; Katao et al. 2014), the source fault of this earthquake was westward dipping, and the aftershock distributions of these studies suggest that both the fault length and width are about $8 \mathrm{~km}$.

The strong ground motions during the 2013 Awaji Island earthquake were widely observed within the basin. The ground motion lasted longer than $3 \mathrm{~min}$ in the Osaka Plain where its bedrock depth varies from approximately 1 to $2 \mathrm{~km}$. The long-duration ground motions are thought to have been due to surface waves excited within the sedimentary basin, whereas the rupture duration was thought to have been less than $5 \mathrm{~s}$ because of its moderate magnitude.

In this study, we modelled long-period (longer than $2 \mathrm{~s}$ ) ground motions during this earthquake to evaluate, with respect to observed data, the degree of validity of the UMC2013 model and to obtain better constraint of the attenuation factor of the sedimentary part of the basin in the velocity structure model. We investigated whether anomalous amplification at a period of $6.5 \mathrm{~s}$ in the Osaka plain were reproduced by the present model, and to identify the cause of strong amplification around this period from data analysis. Such a study is commonly achieved by simulating ground motions of moderate earthquakes, such as the 2013 Awaji Island earthquake. This earthquake occurred in the mountainous area surrounding the Osaka Basin and its epicentre was within the area modelled by the UMC2013 model. Therefore, propagation path effects between the source and the basin, which can distort the seismic waveforms, were not significant. This is an advantage regarding the use of this event as a benchmark for the sedimentary velocity structure model of the Osaka Basin. 


\section{OBSERVED GROUND MOTIONS DURING THE 2013 AWAJI ISLAND EARTHQUAK E}

We collected records of the observed ground motion in and around the Osaka sedimentary basin, in the form of acceleration time histories from the K-NET and KiK-net stations operated by NIED (Aoi et al. 2011), the Seismic Intensity Observation Network Systems of the JMA, Osaka, Hyogo, Kyoto, Wakayama and Nara prefectures and the city of Kyoto (Nishimae 2004), the Building Research Institute (BRI; Kashima 2004), and Port and Airport Research Institute (PARI; Nozu 2004). The strong motion stations belonging to the Committee of Earthquake Observation and Research in the Kansai Area (CEORKA; Kagawa et al. 2004a) and the Disaster Prevention Research Institute of Kyoto University (DPRI) provided strong motion data obtained by the three-component broadband velocity sensors at each station.

The ground motions of the 2013 Awaji Island earthquake were recorded at more than 100 strong motion stations inside the Osaka sedimentary basin. Fig. 2(a) shows the spatial distribution of the observed peak ground velocity (PGV) in and around Osaka Basin and Fig. 2(b) shows the spatial distribution of the observed pseudo velocity response spectra $(\mathrm{pSv}, h=0.05)$ at a period of $6.5 \mathrm{~s}$ in and around the basin. The largest PGV observed in Awaji Island was $42.9 \mathrm{~cm} \mathrm{~s}^{-1}$. Most of the strong motion stations in Awaji Island, whose epicentral distances were less than $20 \mathrm{~km}$, recorded values of $\mathrm{PGV}>10 \mathrm{~cm} \mathrm{~s}^{-1}$. The observed PGV of strong motion stations in the Osaka Plain, whose epicentral distances were about 50-75 km, were $<5 \mathrm{~cm} \mathrm{~s}^{-1}$. However, the pSv at $6.5 \mathrm{~s}$, observed at many stations in the Osaka Plain, were significantly larger compared with other stations with similar distances outside of the basin. The observed $\mathrm{pSv}$ at a period of $6.5 \mathrm{~s}$ exceeded $5 \mathrm{~cm} \mathrm{~s}^{-1}$ at some stations in the Osaka Plain, which are comparable with the observed pSv in

(a)

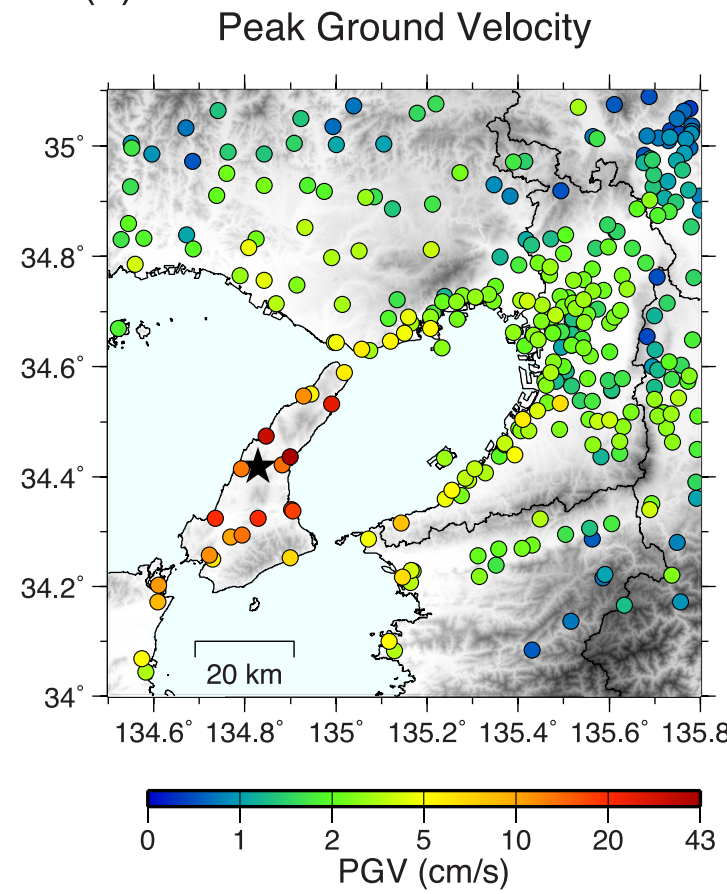

NS

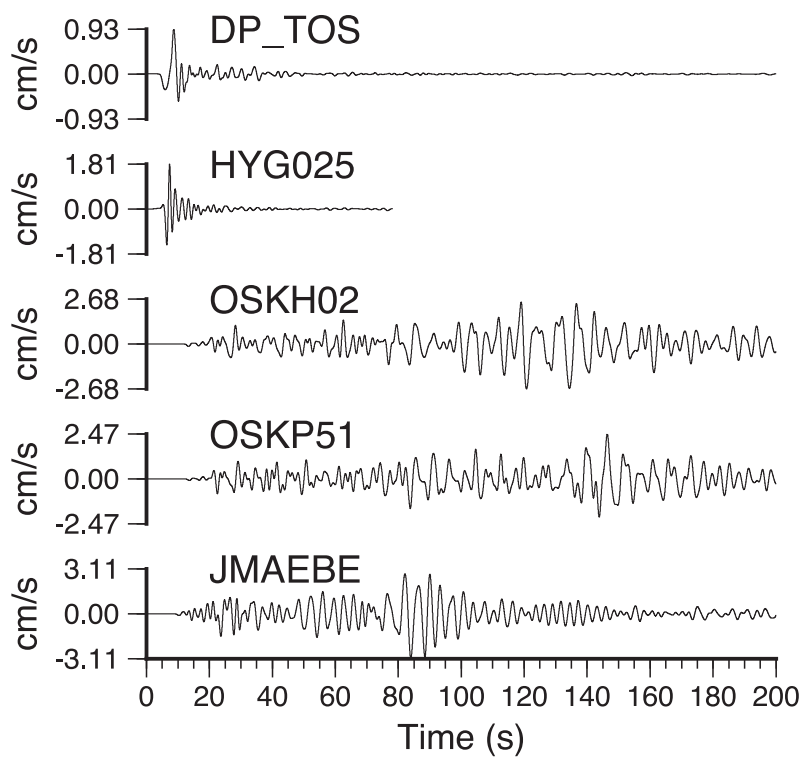

Figure 3. Examples of velocity waveforms observed at strong motion stations of Awaji Island and Osaka Basin. The $\mathrm{N}-\mathrm{S}$ components are shown. Observed waveforms were bandpass filtered between 0.05 and $0.5 \mathrm{~Hz}$. Locations of these strong motion stations are shown in Fig. 4.

the near-source area. This observed ground motion characteristic suggests the amplification of ground motions within this period range.

Fig. 3 shows examples of the velocity waveforms observed at two stations in Awaji Island and three stations in the Osaka Plain. The waveforms are bandpass filtered between 0.05 and $0.5 \mathrm{~Hz}$ and the (b)

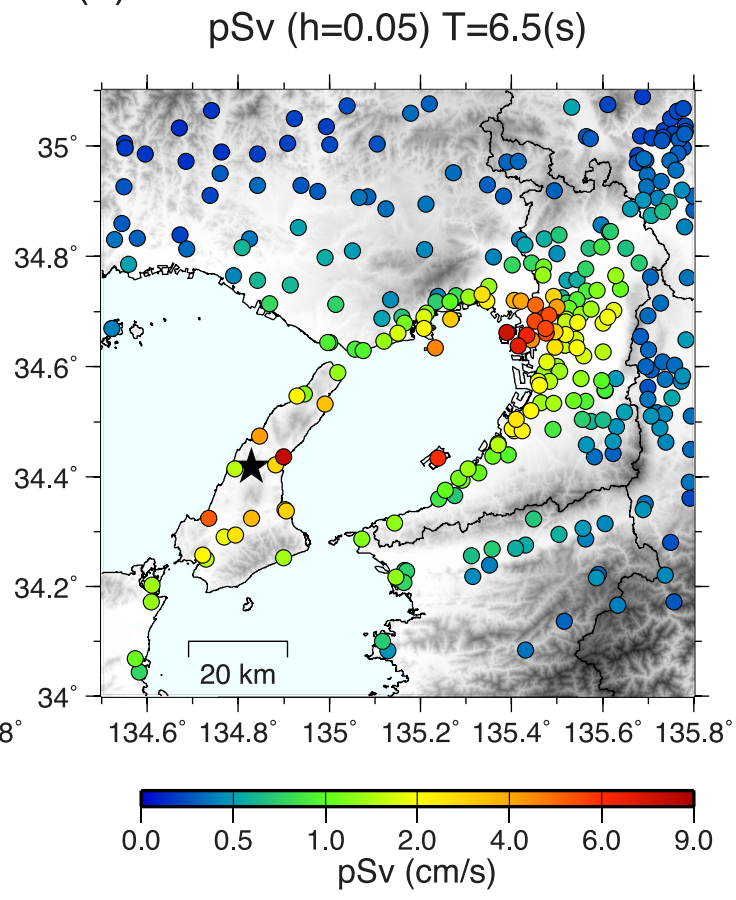

Figure 2. (a) Spatial distribution of peak ground velocity (PGV) in and around Osaka Basin during the 2013 Awaji Island earthquake. Solid star denotes the epicentre of the 2013 Awaji Island earthquake. (b) Spatial distribution of pseudo response velocity spectra (pSv) at a period of $6.5 \mathrm{~s}$ with damping factor $(h)$ of 5 per cent obtained from the strong motion records in and around Osaka Basin. 


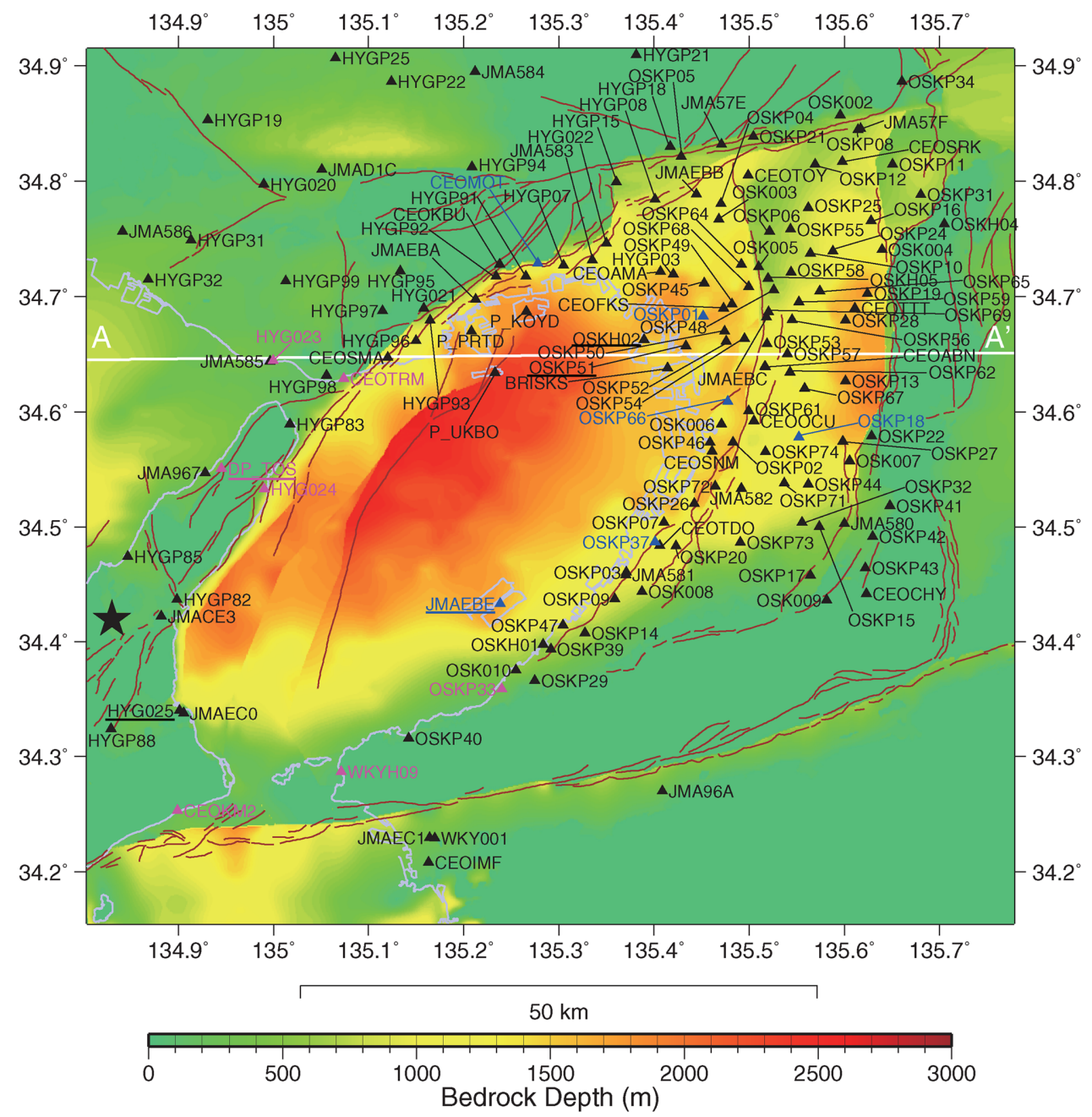

Figure 4. Osaka Basin and surrounding area. Colour contours represent bedrock depth distribution of the UMC2013 velocity structure model. Brown traces denote active faults on the ground surface compiled by AIST (2007). The black star denotes the epicentre. Triangles indicate the strong motion stations for which the observed and simulated ground motions were demonstrated. The stations appeared in Fig. 3 are underlined. The stations used in Figs 6 and 7 are indicated by magenta and blue colours, respectively. Solid line A-A' represents line of profile shown in Fig. 5.

$\mathrm{N}-\mathrm{S}$ component of the ground motion is shown in this figure. Note that the ground motions are characterized by elongated duration and amplified late arrivals, particularly within the period range of 6-7 s at the stations along Osaka Bay in the Osaka Basin where sedimentary thickness reaches $1-2 \mathrm{~km}$. Fig. 4 displays the locations of the strong motion stations at which the records used in this study were collected.

\section{3-D GROUND MOTION SIMULATION USING THE FINITIE DIFFERENCE METHOD (FDM)}

\subsection{3-D velocity structure model in the Osaka Sedimentary Basin}

Sekiguchi et al. (2013) developed the UMC2013 model for the prediction of strong ground motion for a hypothetical earthquake on the Uemachi Fault system, which lies in the Osaka Basin. Their model was based on the earlier model of Horikawa et al. (2003), but it incorporated newly obtained exploration data to supplement the existing data, and it applied new methodology to describe the 3 -D shape of the bedrock and key horizons. The original model of Horikawa et al. (2003) was used in the ground motion prediction for a hypothetical Nankai earthquake by Sekiguchi et al. (2008) and a brief description of that velocity structure model is available in that paper. Sekiguchi et al. (2013) integrated geophysical and geological information from 60 reflection profiles, 89 deepboring exploration logs, Rayleigh wave phase-velocity curves from 65 microtremor array observations, microtremor $\mathrm{H} / \mathrm{V}$ spectra at 110 sites and PS-P traveltimes from receiver function analyses of earthquake records from 82 strong motion stations within the basin. The basic information on the model is given in the following paragraphs.

The sedimentary part and the bedrock surface of the model was divided into 16 blocks in order to describe the discontinuity appearing in bedrock depth, which was formed by active faults, in the same way as Horikawa et al. (2003). The $P$-wave velocity $\left(V_{\mathrm{P}}\right)$ at a specific depth for a specific location was derived from a function of burial depth and depositional age of the sediment at that depth in the similar way as in Horikawa et al. (2003). The sediments within 
the basin consist mostly of the upper Pliocene to middle Pleistocene called the Osaka Group and no significant unconformity was found within the Osaka Group (e.g. Itihara et al. 1997). Hence, the depositional age profile along the depth was reasonably obtained by the interpolation of the depths of several key horizons or key beds. Following Horikawa et al. (2003), we chose five key horizons of marine clays (Ma10, Ma3 and Ma-1), Fukuda Tephra, Matsuyama/Gauss geomagnetic polarity boundary. These key horizons were selected considering their spatial extents in the Osaka basin and time intervals between horizons. The depositional age of marine clays Ma10, Ma3 and Ma-1 are assumed to be $0.3,0.85$ and 1.3 Ma (Mega Annum), respectively. The depositional age of Fukuda Tephra is assumed to be $1.7 \mathrm{Ma}$, which is close to the boundary of Calabrian and Gelasian stages in Pleistocene. The age of Matsuyama/Gauss polarity boundary is assumed to be $2.6 \mathrm{Ma}$, which corresponds to the Pliocene-Pleistocene boundary. The depositional age of the ground surface referred to the 1:200 000 digital geological map of Japan (Geological Survey of Japan 2012). The interpolated depositional age profile is smoothly continuous with depth, thus the velocity model within the sedimentary part has no explicit discontinuity. We also modelled the top of the Kobe Group, which is Miocene sedimentary rocks existing beneath the Osaka Group in limited parts of the basin. The top of the bedrock (preTertiary rocks), which corresponds to the most significant unconformity and the origin of the velocity discontinuity, was modelled based on available exploration datasets described above. The $S$-wave velocity $\left(V_{\mathrm{S}}\right)$ was derived from the empirical relationship between $V_{\mathrm{P}}$ and $V_{\mathrm{S}}$ proposed by Nakagawa et al. (1996) and the density was obtained using Gassmann's equation (Gassmann 1951). Thus, the sediments within the basin were expressed as a volume with spatially variable seismic velocities and densities, rather than as a stack of layers with constant material parameters. The model parameters are described with continuous functions, whereas the previous model by Horikawa et al. (2003) gave model parameters at $100 \mathrm{~m}$ intervals along the horizontal axis and $50 \mathrm{~m}$ intervals along the vertical axis. In the simulation, model parameters were sampled at $50 \mathrm{~m}$ intervals along both horizontal and vertical axes. The lowest $V_{\mathrm{P}}$ and $V_{\mathrm{S}}$ of the sedimentary part of this model were 1.5 and $0.25 \mathrm{~km} \mathrm{~s}^{-1}$, respectively. The available geophysical information used for development of this 3-D velocity structure model such as reflection survey, deepboring, microtremor survey and so on were limited largely inside the Osaka Basin because the main target of this development is to have a model to be used for ground motion simulations inside the Osaka basin. Thus, the bedrock depth and velocity structure of the model in the area outside the basin were constrained by the gravity anomaly and surface geology map only because of the lack of reflection and deep-boring data.

The spatial distribution of the bedrock depth of the present model is shown in Fig. 4. Fig. 5(a) shows the vertical section of the depositional age along the profile $\mathrm{A}-\mathrm{A}^{\prime}$ of UMC2013 model and Fig. 5(b) shows its vertical section of the $S$-wave velocity along the same line. The lateral irregularity of bedrock depth and sedimentary layers, caused by the vertical offsets along the Rokko, Osaka Bay, Uemachi and Ikoma active fault systems, can be seen clearly in these maps and cross sections. As explained above, the $S$-wave velocity in the sedimentary part smoothly increases with depth.

A horizontally layered velocity structure model was assumed for the crust below the bedrock. The model parameters were specified following Horikawa et al. (2003) and they are listed in Table 1. Horikawa et al. (2003) developed this layered velocity structure model based on the studies by Maeda \& Watanabe (1984) and Kagawa et al. (1990).
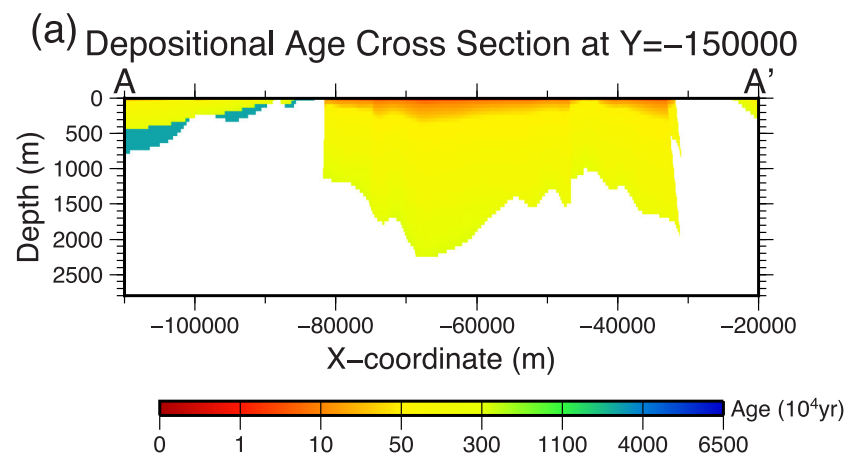

(b)

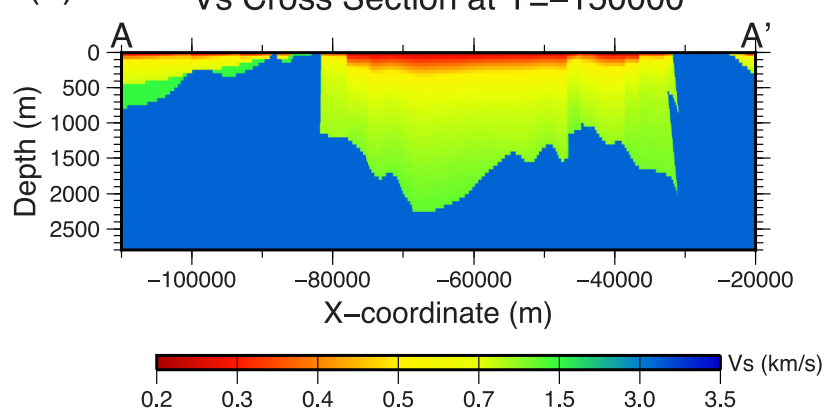

Figure 5. (a) Vertical section of the depositional age distribution of the UMC2013 model along profile A-A' (Fig. 4). (b) Vertical section of the $S$-wave velocity structure along profile A-A' (Fig. 4).

Table 1. Model parameters of the crustal structure models beneath the bedrock assumed in the ground motion simulations.

\begin{tabular}{ccccc}
\hline Top depth $(\mathrm{km})$ & $V_{\mathrm{P}}\left(\mathrm{km} \mathrm{s}^{-1}\right)$ & $V_{\mathrm{S}}\left(\mathrm{km} \mathrm{s}^{-1}\right)$ & Density $\left(\mathrm{g} \mathrm{cm}^{-3}\right)$ & $Q$ \\
\hline Variable & 5.5 & 3.1 & 2.6 & 200 \\
3.0 & 6.0 & 3.5 & 2.7 & 300 \\
15.0 & 6.6 & 3.8 & 2.8 & 400 \\
\hline
\end{tabular}

\subsection{FDM simulation}

The 3-D ground motion simulation was conducted using the finite difference method (FDM). A staggered grid FDM scheme in the velocity-stress formulation with fourth-order accuracy in space and second-order accuracy in time was used to solve the elastodynamic wave equations (e.g. Virieux 1986; Levander 1988; Yomogida \& Etgen 1993; Graves 1996; Pitarka 1999). The source was implemented via the moment tensor source formulation that uses the stress components (Pitarka 1999). The zero-stress formulation was introduced for the free surface boundary condition at the top of the model space (e.g. Levander 1988; Graves 1996). A perfectly matched layer (PML) was applied to the model boundaries, except for the free surface, to avoid non-physical reflections. Here, we used the multiaxial PML (M-PML) absorbing boundary condition (Meza-Fajardo \& Papageorgiou 2008; Zeng et al. 2011). The grid thickness of the PML domain was set to 10 grids. An inelastic attenuation effect was included in the form of a linear frequency dependent $Q$ operator, following the method proposed by Graves (1996). The verification of the FDM code used is essential to this kind of numerical works (e.g. Day et al. 2001, 2003; Yoshimura et al. 2012; Moczo et al. 2014), some verification tests using canonical models are given in Supporting Information (Figs S1, S2 and S3).

Our FDM model space occupied a $90(\mathrm{E}-\mathrm{W}) \times 85 \mathrm{~km}(\mathrm{~N}-\mathrm{S})$ area in and around the Osaka sedimentary basin, corresponding to 
the geographical area shown in Fig. 4, and it extended to a depth of $25.5 \mathrm{~km}$ below the ground surface. The model was discretized using a uniform $0.05-\mathrm{km}$ grid along the horizontal and vertical axes. The technique developed by Moczo et al. (2002) was used to implement the UMC2013 model. The number of gridpoints was $1801 \times 1701$ $\times 512=1568512512$. As the elevation of most strong motion stations inside the basin was less than one grid size, our simulation did not consider surface topography. The minimum $S$-wave velocity of the original model was approximately $0.25 \mathrm{~km} \mathrm{~s}^{-1}$. Hence, this calculation was generally valid up to $0.83 \mathrm{~Hz}$ with a sampling of six gridpoints per minimum wavelength. The near-surface sediments have relatively high Poisson's ratio $\left(V_{\mathrm{P}} / V_{\mathrm{S}} \sim 6\right)$ in our velocity structure model, thus this soft sediments might affect the accuracy in the numerical simulation. Considering the examinations done by Moczo et al. (2011), we set the target frequency range to 0.05$0.5 \mathrm{~Hz}$ in order to give at least 10 grids per minimum wavelength near the surface for safety.

The 3-D wave propagation was simulated for $270 \mathrm{~s}$ after the origin time with an increment of $0.0025 \mathrm{~s}$, that is the total number of time steps in this simulation was 108000 . The simulation was performed using the Cray XE6 supercomputer of the Academic Center for Computing and Media Studies of Kyoto University that has two 16-core AMD Opteron Interlagos processors with a clock speed of $2.5 \mathrm{GHz}$ in each node. We used 512 cores from 16 nodes for each run. The Message Passing Interface (MPI) was used for the interprocess communication, and the computation within a process was parallelised using the OpenMP. It took about $23 \mathrm{hr}$ to complete one run.

\subsection{Source model of the 2013 Awaji Island earthquake}

The source model of the 2013 Awaji Island earthquake in the ground motion simulation was represented by a double-couple point source that had a bell-shaped source time function with one pulse (Fig. 6a). The bell-shaped source time function is defined as

$f(t)= \begin{cases}\frac{M_{0}}{T_{0}}\left[1-\cos \left(\frac{2 \pi}{T_{0}} t\right)\right] & \text { if } 0 \leq t \leq T_{0} \\ 0 & \text { if } t<0 \text { or } t>T_{0}\end{cases}$

where $t$ is the time from rupture initiation time, $M_{0}$ is seismic moment and $T_{0}$ is source duration time or rise time.

The epicentre was fixed at the location routinely determined by the JMA. The focal mechanism and seismic moment were assumed based on the moment tensor solution released by F-net of NIED. The strike, dip, and rake angles were $179^{\circ}, 65^{\circ}$ and $102^{\circ}$, respectively. The seismic moment was $5.47 \times 10^{17} \mathrm{Nm}\left(M_{\mathrm{w}} 5.8\right)$. The source depth and duration time were estimated using a grid search to fit the observed waveforms in the target period range at seven nearby

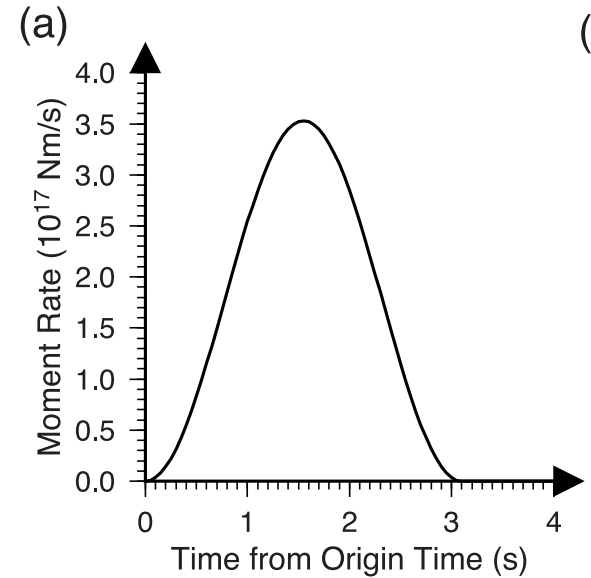

(b)

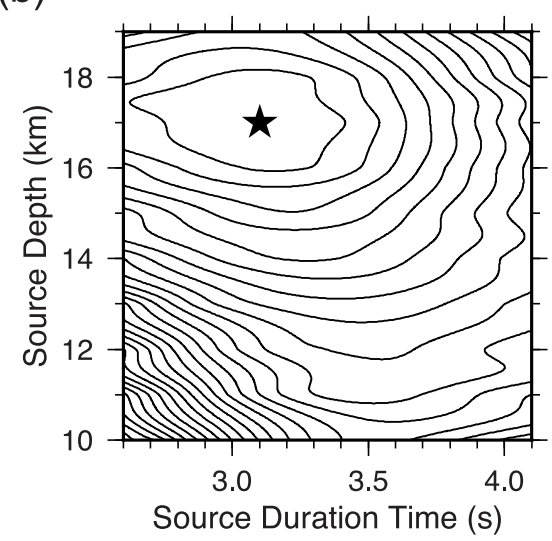

(c)
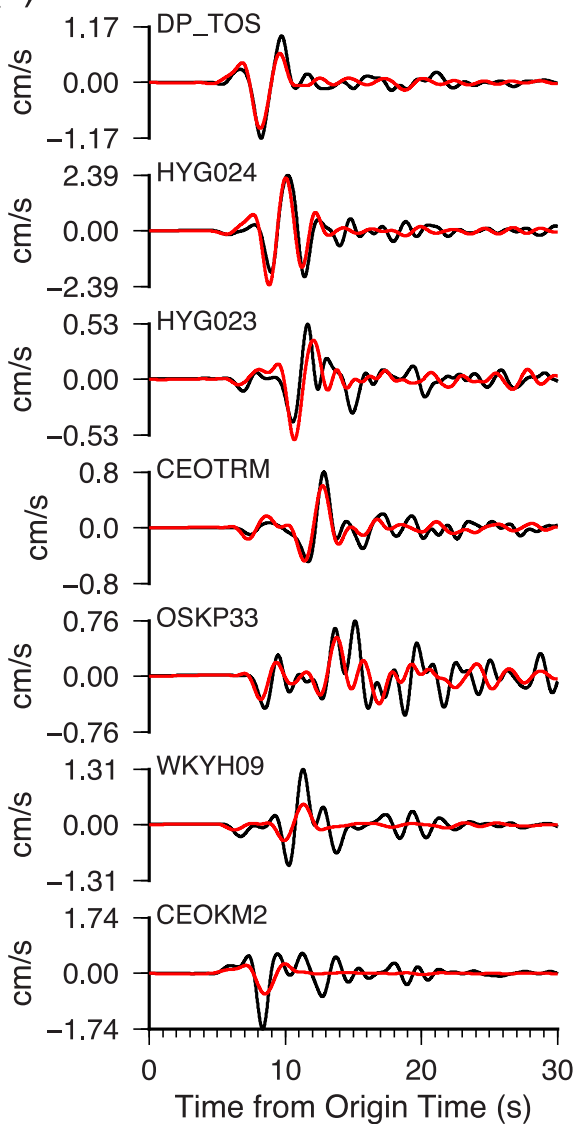

Figure 6. (a) The source-time function used in the simulation. (b) Contours of cross-correlation coefficient as a function of the source duration time and source depth. Best solution is indicated by the solid star. (c) Comparisons of the observed velocity waveforms (black) and simulated velocity waveforms (red) at seven nearby rock stations. The waveforms of $\mathrm{E}-\mathrm{W}$ component in the frequency range $0.05-0.5 \mathrm{~Hz}$ are shown. See Fig. 4 for the locations of each strong motion station. 
rock stations outside the sedimentary basin (DP_TOS, CEOKM2, CEOTRM, HYG023, HYG024, OSKP33 and WKYH09). The simulation in the grid search was done by the FDM with the same velocity structure model but with a reduced area $(50 \mathrm{~km}$ in $\mathrm{EW}$ direction and $60 \mathrm{~km}$ in NS direction) and shorter duration (30 s).

As shown in Fig. 6(b), the source depth and duration time were estimated to be $17 \mathrm{~km}$ and $3.1 \mathrm{~s}$, respectively. The examples of waveform fittings at these stations is shown in Fig. 6(c). The duration of the direct $S$-wave pulse was reproduced well except two stations (CEOKM2 and WKYH09) in the southeast direction from the epicentre, where the amplitude was a little underestimated. These stations might be affected by the forward rupture directivity effect because of relatively short epicentral distances, thus the point source might not be an adequate approximation for these stations. In order to improve the amplitude and pulse duration at the close stations, we need to consider finite source effects. On the other hand, the Osaka plain, which is the main target area of this study, is far from the epicentre, whose epicentral distance $(>50 \mathrm{~km})$ is much larger than an expected source size, and the azimuth from the source is almost perpendicular to the fault strike. Rupture directivity effect will not be significant in the target period range. We also tested the effects of uncertainty in the dip angle, and it did not significantly affect simulation results (Fig. S4). Therefore, we decided to use a point source approximation in our FDM simulation of this event.

\subsection{Estimation of appropriate $Q$-factor in the sediments}

The $Q$-factor controlling attenuation of seismic waves is another important medium parameter for simulating the seismic wavefield inside a sedimentary basin (e.g. Olsen et al. 2003). In our FDM simulation, the inelastic attenuation effect was included following the method proposed by Graves (1996), which is used in many ground motion simulations using FDM (e.g. Aoi \& Fujiwara 1999; Pitarka et al. 2004; Yamada \& Horike 2007; Kawabe \& Kamae 2008; Iwaki \& Iwata 2011; Morikawa et al. 2011; Uebayashi et al. 2012; Yoshimura et al. 2012; Dhakal \& Yamanaka 2013). In this method, the velocity and stress components are multiplied by the following factor $(A)$ at each time step:

$A=\exp \left(-\frac{\pi f_{0} \Delta t}{Q_{0}}\right)$,

where $\Delta t$ is a time step interval and $Q_{0}$ is $Q$ at the reference frequency $f_{0}$ (in $\mathrm{Hz}$ ). This form implies that $Q$ is linearly dependent on frequency:

$Q(f)=Q_{0} \frac{f}{f_{0}}$.

In previous studies of the Osaka Basin (e.g. Horikawa et al. 2003; Yamada \& Horike 2007; Kawabe \& Kamae 2008; Iwaki \& Iwata 2011; Uebayashi et al. 2012), the above inelastic attenuation model proposed by Graves (1996) were used, and $Q_{0}$ is commonly given by a function of $V_{\mathrm{S}}\left(\right.$ in $\left.\mathrm{m} \mathrm{s}^{-1}\right)$ :

$Q_{0}=\alpha V_{\mathrm{S}}$.

In this study, to determine an appropriate $Q$-factor for the UMC2013 model, we searched for the best value of $\alpha$ among five cases $(\alpha=1.0,0.5,0.3,0.2$ and 0.1$)$ when the reference frequency $f_{0}$ was fixed at $0.2 \mathrm{~Hz}$, considering the dominant period range of observed ground motions in the Osaka sedimentary basin. The longduration records of this event provided a good opportunity to perform this type of study because it is difficult to observe differences in waveform fittings for different values of $\alpha$ with short-duration records.

We compared the simulated ground motions with those observed in terms of the rms velocity envelopes at 51 strong motion stations inside the Osaka Basin. Before calculating the rms envelope, the velocity waveform was bandpass filtered between 0.05 and $0.5 \mathrm{~Hz}$. Based on the residual between the observed and simulated rms velocity envelopes evaluated by the $L^{2}$-norm at 51 strong motion stations, the best value of $\alpha$ was determined to be 0.3 . Fig. 7 shows the comparison of the observed and simulated rms velocity envelopes at six of the strong motion stations. It can be seen that when $\alpha=0.1$, the amplitude of the simulated velocity waveform decays faster than the observation, that is the late arrivals that dominate within the sedimentary basin are underestimated. However, the late arrivals are somewhat overestimated when $\alpha=1.0$. The variation of the residuals is not significant when $\alpha=0.2-0.5$, but a value of $\alpha=0.3$ provides the best results among the five tested cases (Fig. 8); thus, $\alpha=0.3$ was used for the coefficient of eq. (3) in this study.

\subsection{Results of FDM simulation}

Fig. 9 shows the comparison between the observed and simulated velocity waveforms at 46 stations among the 152 stations shown in Fig. 4. Comparison for all of the 152 stations are shown in Fig. S5. The waveforms were bandpass filtered at frequencies of $0.05-0.5 \mathrm{~Hz}$. In the figure, the stations are ordered according to epicentral distance and the agreement between the observed and simulated velocity waveforms is reasonable in terms of both amplitude and ground motion duration. In particular, during the first $60 \mathrm{~s}$ for the direct $P$ - and $S$-wave arrivals, the amplitude and phase of the simulated waveforms match the observed waveforms reasonably well at most stations within the Osaka Basin, which means that the velocity structure model for the land area of the Osaka Basin is satisfactory. However, some stations outside the Osaka Basin (e.g. HYGP82 and JMAEC0 in Awaji Island, HYGP32 and JMA586 to the northwest of the basin, CEOIMF and JMA967 to the south of the basin, and OSKP34 to the northeast of the basin) show underestimations of amplitude and ground motion duration due to the lack of accurate information on the local subsurface velocity structure outside of the basin. This is expected because the bedrock depth and sedimentary layers outside the basin are not constrained well by the existing geophysical data, as explained in the introduction to the model. For HYGP18, OSKP05, OSKP21 and OSK002, located close to the Arima-Takatsuki Tectonic Line that lies north of the Osaka basin, the agreement between the observed and synthetic waveforms is also relatively poor. This suggests the necessity for improvement in the detailed geometry of the basin edge and sedimentary layers along the fault zone by considering the sedimentation history of this area.

The comparison between the synthetic and observed horizontal $\mathrm{pSv}$ at six different periods, 2.0, 3.0, 4.0, 5.0, 6.0 and $6.5 \mathrm{~s}$, which cover the predominant periods of long-period ground motions in the Osaka Basin are shown in Fig. 10. The horizontal pSv is measured using the geometric mean of $\mathrm{pSv}$ values from two horizontal components. For the period range $2-3 \mathrm{~s}$, the difference between the observed and synthetic pSv are small and spatially uncorrelated. However, for a longer period range (5-7 s), a remarkable underestimation of $\mathrm{pSv}$ can be seen in the central part of the Osaka Plain or the bay area in the latitude range of $34.6-34.7^{\circ} \mathrm{N}$ between Osaka Bay and the Uemachi Fault system, which lies on the opposite side of Osaka Bay to the epicentre. Because the waveforms in the 
OSKP01

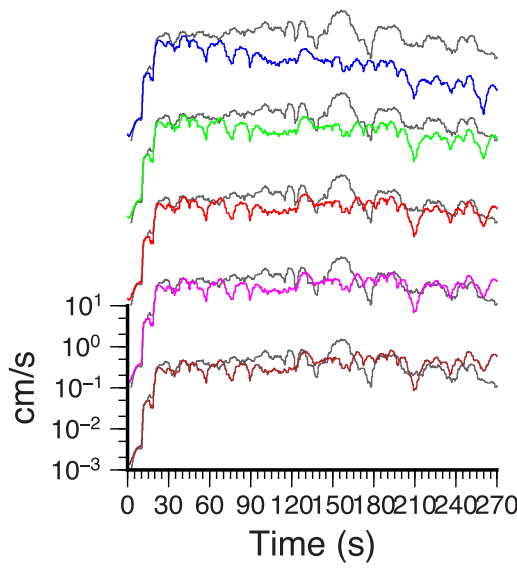

JMAEBE

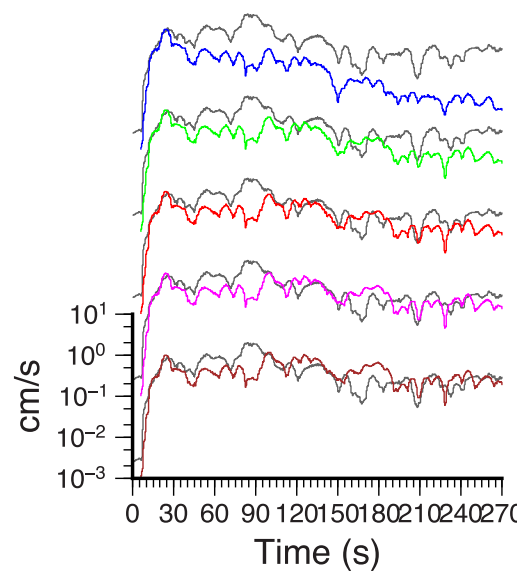

OSKP37

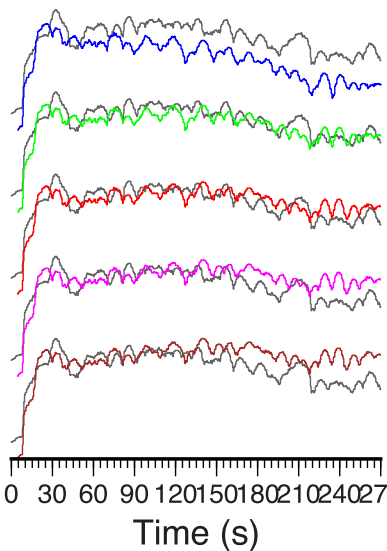

OSKP18

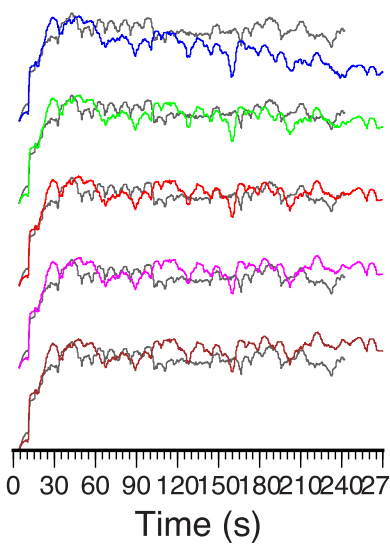

OSKP66

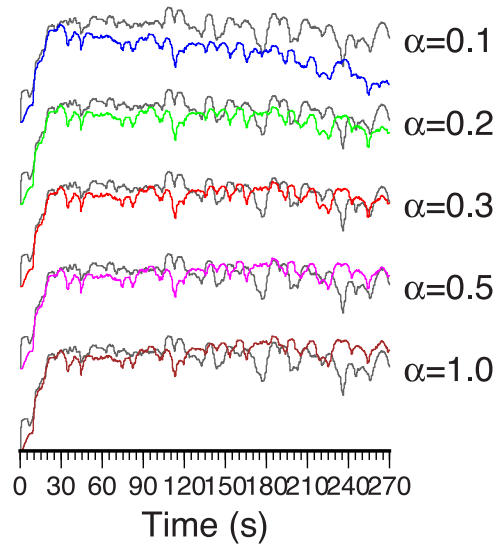

CEOMOT

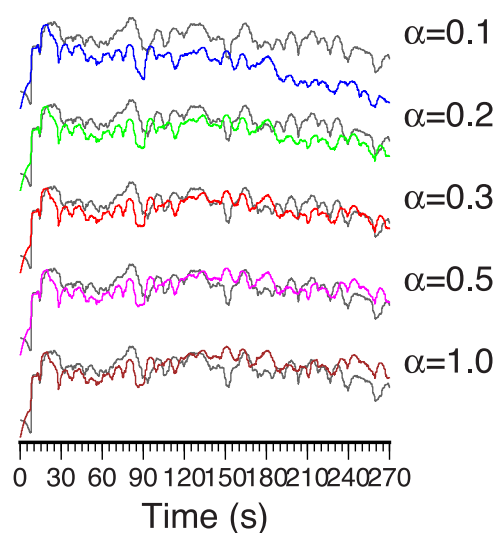

Figure 7. Comparisons between the observed and simulated rms envelopes of N-S components at six strong motion stations inside Osaka Basin. Different colours correspond to different values of $\alpha$.

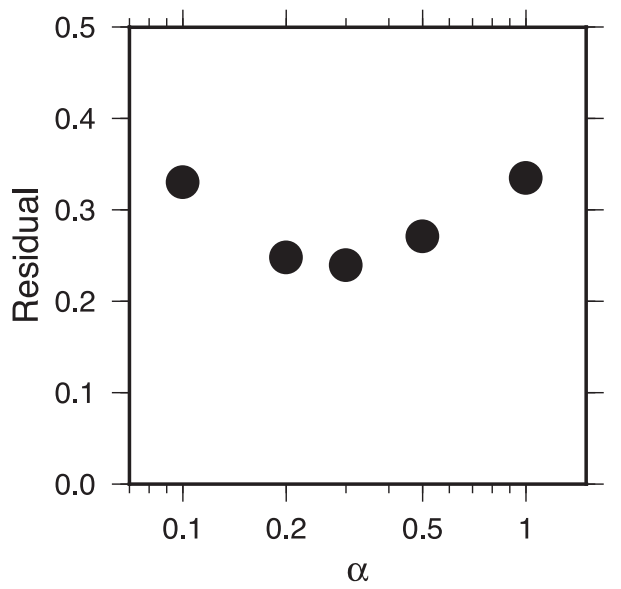

Figure 8. Residual between the observed and simulated rms envelopes averaged by 51 strong motion stations for different values of $\alpha$.

first $60 \mathrm{~s}$ are reproduced well in these stations, as mentioned above (Fig. 9), this discrepancy would be caused by inadequate modelling of later phases within this period range. This point is important for comprehending the performance of the $3-\mathrm{D}$ basin velocity structure model, and it is discussed in detail later in this paper.
The snapshots of simulated seismic wave propagation at 10 -s time steps are shown in Fig. 11. The simulated ground velocity of the NS component is shown. The duration of ground motions are elongated in the Osaka Basin, as is expected from the comparison of the simulated waveforms between the inside and outside of the Osaka Basin shown in Fig. 9. The basin-edge induced surface waves are generated efficiently along the east coast of Awaji Island approximately $10-20 \mathrm{~s}$ after the time of origin. When we consider the surface wave propagation $20-120 \mathrm{~s}$ after the time of origin, it can be seen that these surface waves propagate slowly northeastward in the Osaka Basin. However, they propagate northward when they approach the bay area and do not propagate into the Osaka Plain well. This point will also be discussed later in detail.

\section{DISCUSSION}

\subsection{Comparison with previous studies of $Q$-factor in the Osaka Basin}

As mentioned in the previous section, some earlier studies have investigated the settings of the $Q$-factor for sedimentary layers in the Osaka Basin. Horikawa et al. (2003) gave a value of $\alpha=$ 0.2 for $f_{0}=0.2$. Kawabe \& Kamae (2008) determined a value of 
NS
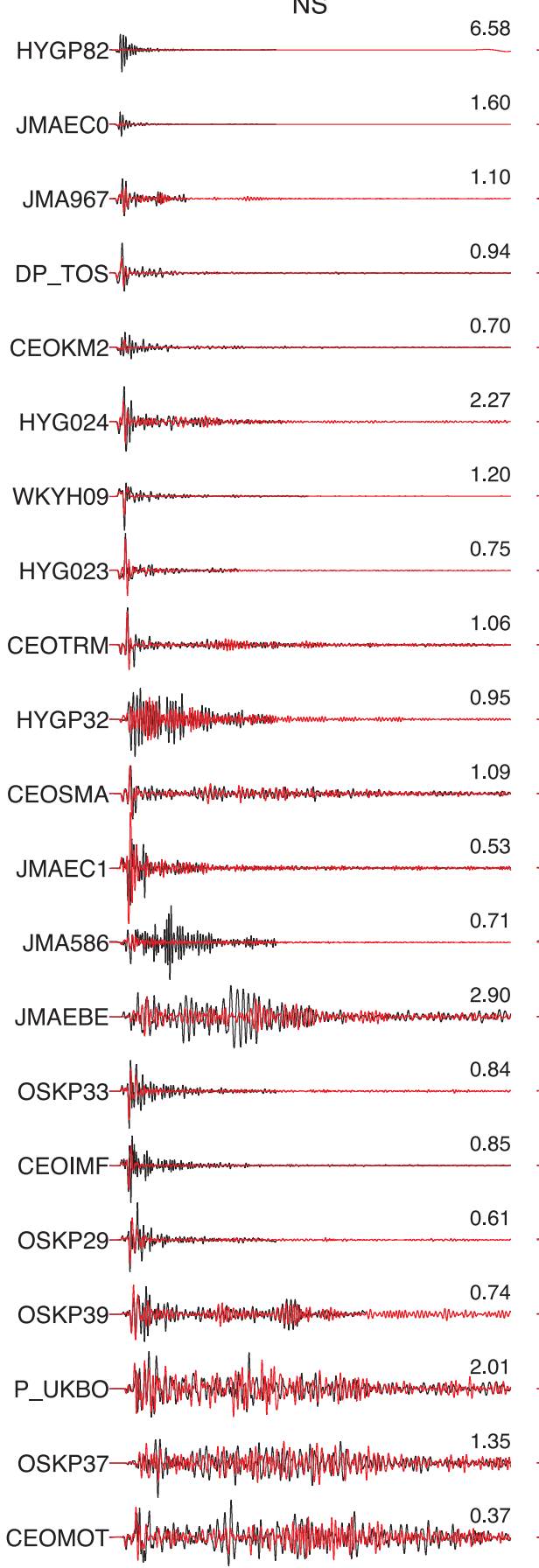

JMA96
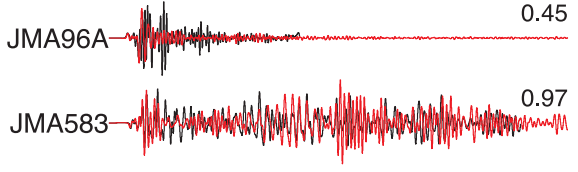

$0 \quad 30 \quad 60 \quad 90 \quad 1201501802102402700$ Time from Origin Time (s)
EW
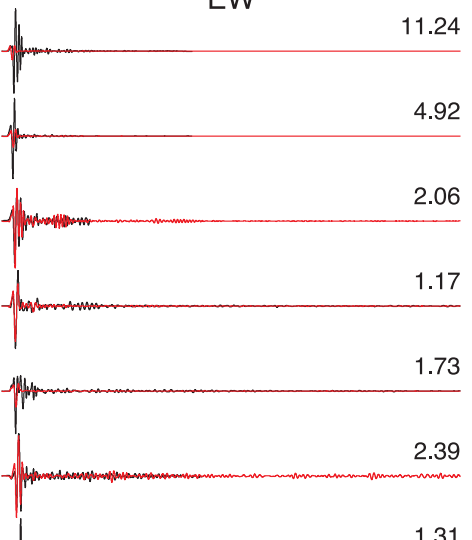

wh
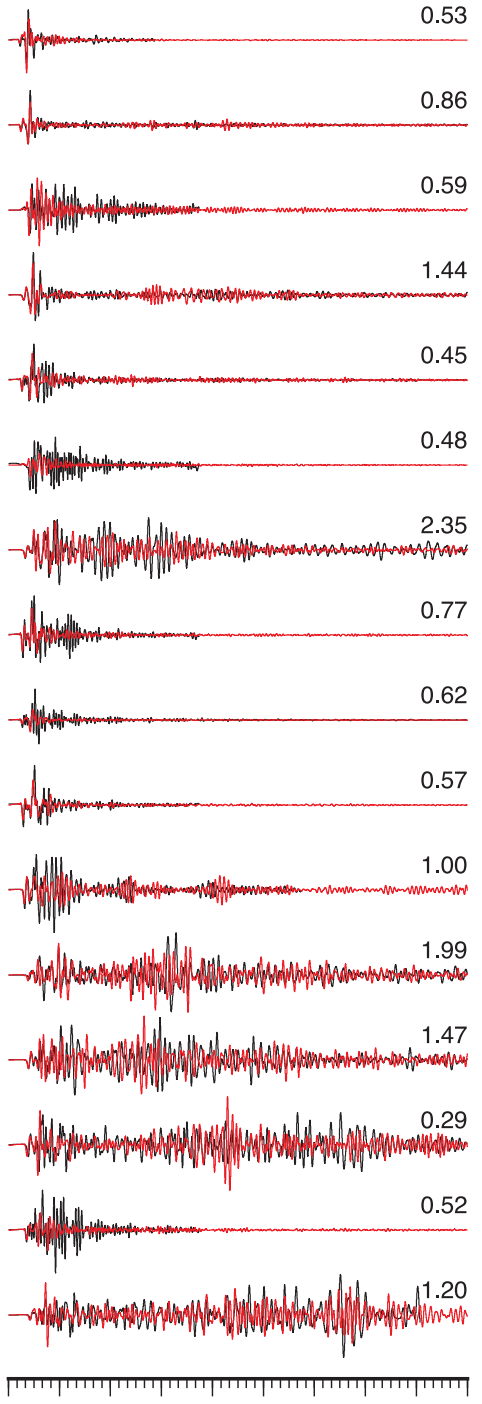

$30 \quad 60901201501802102402700$

Time from Origin Time (s)
UD
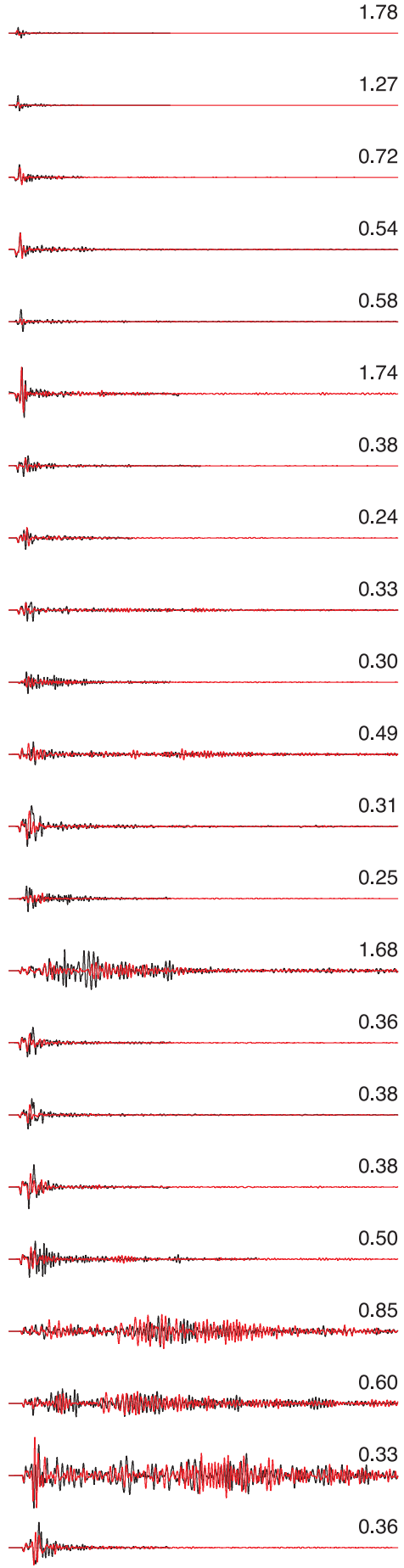

0.36

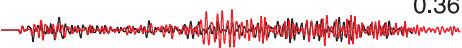

Figure 9. Comparisons of the observed velocity waveforms (black) and simulated velocity waveforms (red). The left-hand, middle and right-hand columns show the waveforms of the $\mathrm{N}-\mathrm{S}, \mathrm{E}-\mathrm{W}$ and up-down components, respectively. The waveforms were bandpass filtered at $0.05-0.5 \mathrm{~Hz}$. Three components are plotted on the same scale and normalized by the maximum observed amplitude for each station. The numbers above the waveforms are the maximum amplitude of the observed waveforms in $\mathrm{cm} \mathrm{s}^{-1}$. See Fig. 4 for the locations of each strong motion station. The stations are ordered by epicentral distance. 


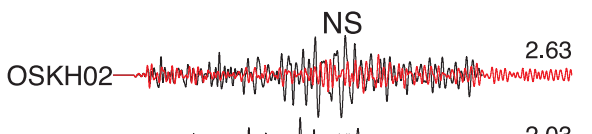

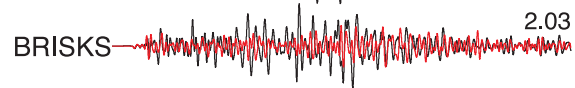

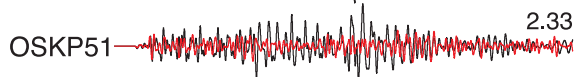

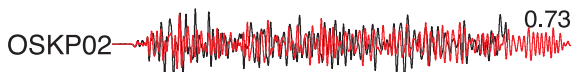

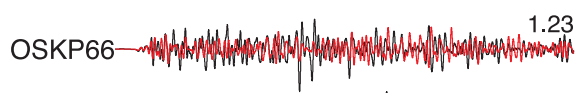
OSKP01-nAwAm 2.19

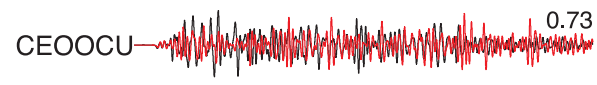
OSKP50- D.w

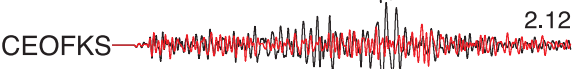

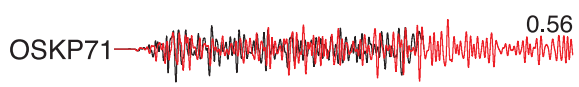

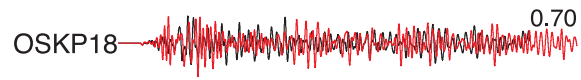

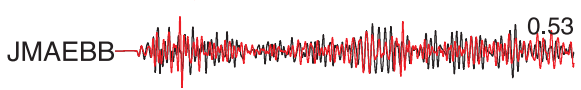

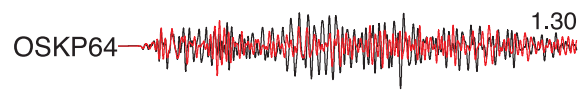

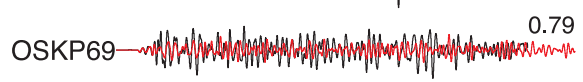

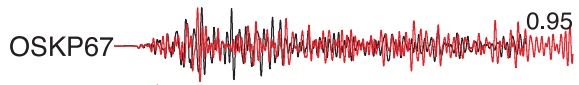

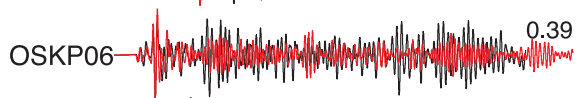

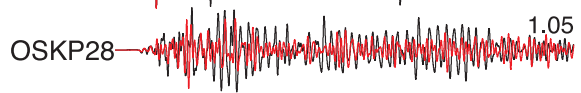

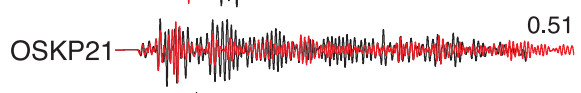

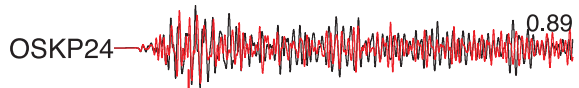

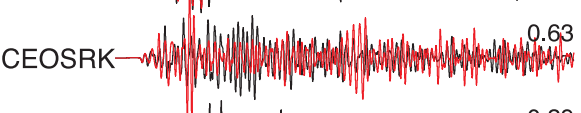

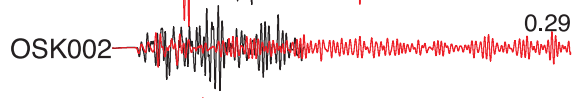

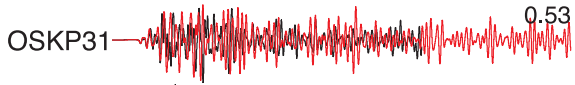

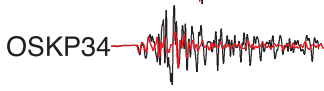

0.14

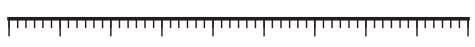

$03060 \quad 901201501802102402700$ Time from Origin Time (s)
EW

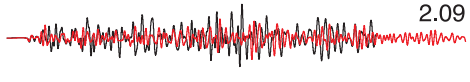

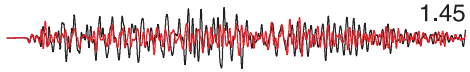

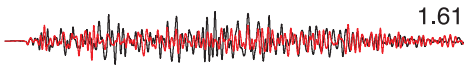

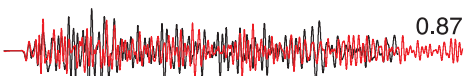

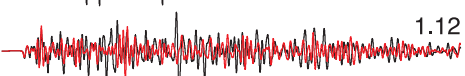

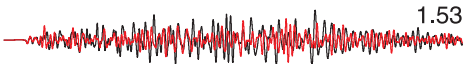

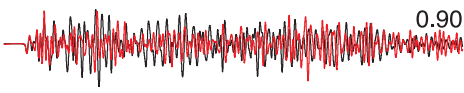

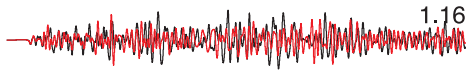

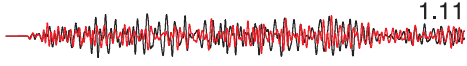

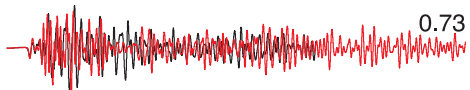

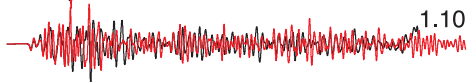

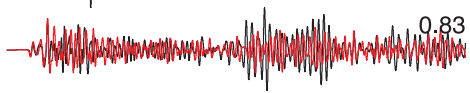

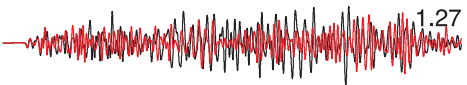

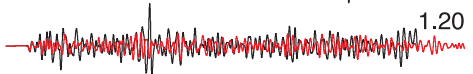

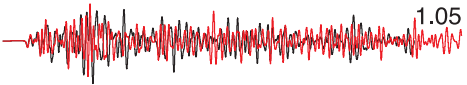

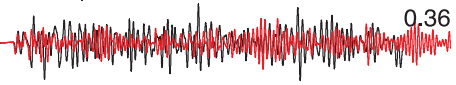

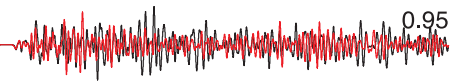

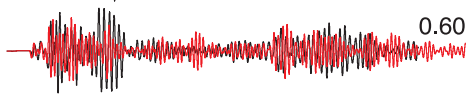

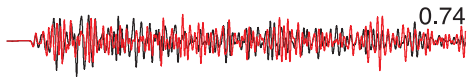

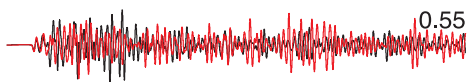
-

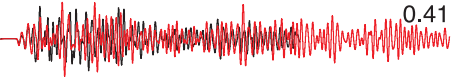

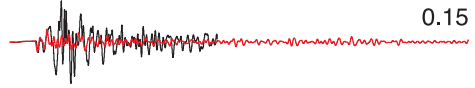
3060901201501802102402700 Time from Origin Time (s)
UD
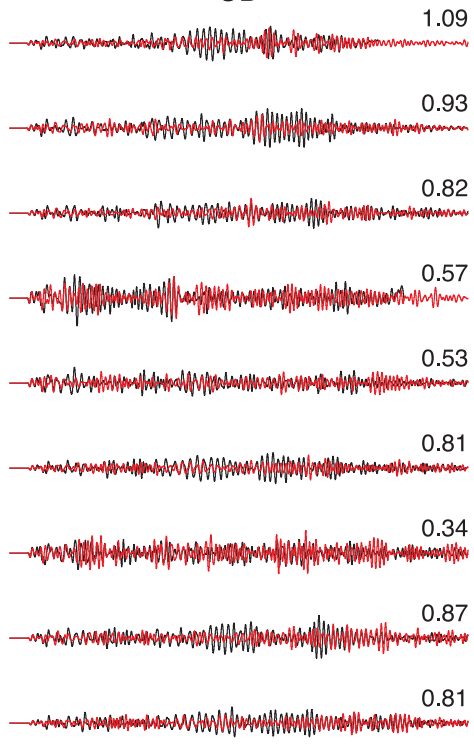

0.39

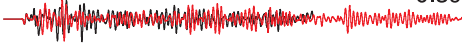
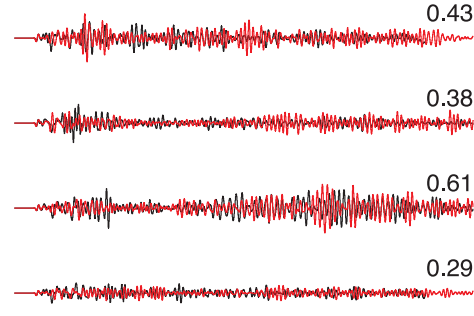

0.47
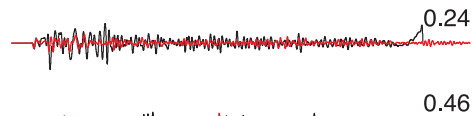

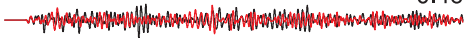
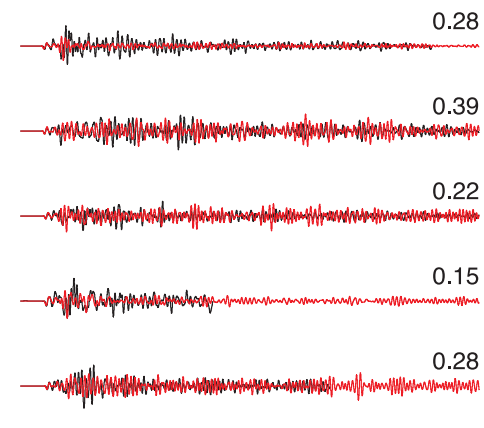

$-m$. 0.11

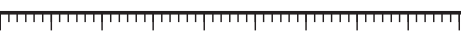

306090120150180210240270 Time from Origin Time (s)

Figure 9. (Continued.) 


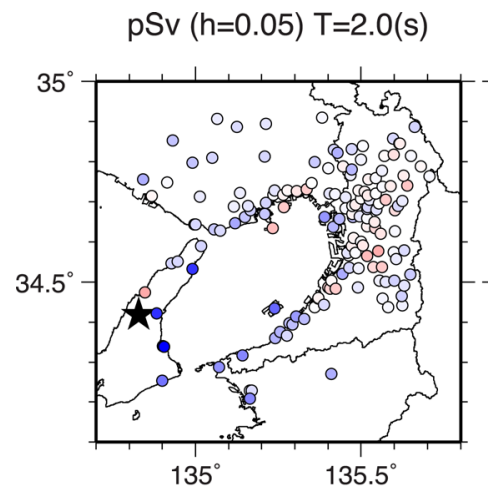

$$
\mathrm{pSv}(\mathrm{h}=0.05) \mathrm{T}=3.0(\mathrm{~s})
$$
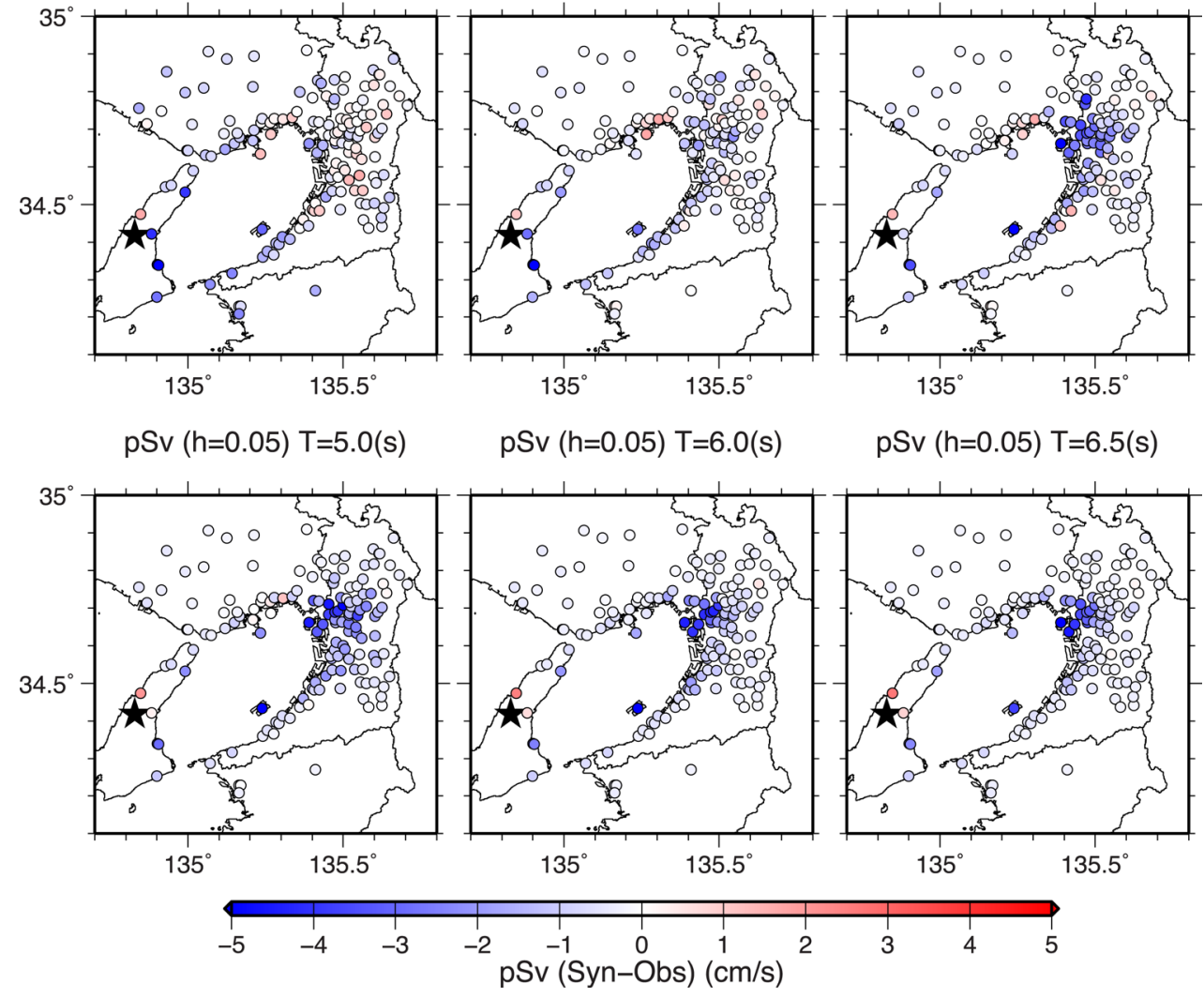

Figure 10. Spatial distributions of difference between the synthetic and observed horizontal pseudo velocity response spectra (pSv) at periods of 2.0, 3.0, 4.0, $5.0,6.0$ and $6.5 \mathrm{~s}$.

$\alpha=0.5$ for $f_{0}=1.0$ based on the ground motion simulation of the 2000 southern Mie intraslab earthquake $\left(M_{\mathrm{w}} 5.4\right.$, depth $\left.35 \mathrm{~km}\right)$, which occurred approximately $100 \mathrm{~km}$ east of the centre of the Osaka Basin. Iwaki \& Iwata (2011) stated a value of $\alpha=0.5$ for $f_{0}=$ 0.33 based on waveform modelling of the 2007 northern Mie earthquake ( $M_{\mathrm{w}} 5.0$, depth $12 \mathrm{~km}$ ), which occurred approximately $90 \mathrm{~km}$ east of the centre of the Osaka Basin, and the 2010 northwest Nara intraslab earthquake $\left(M_{\mathrm{W}} 5.0\right.$, depth $\left.60 \mathrm{~km}\right)$ that occurred southwest of the Osaka Basin. For a fixed reference frequency $f_{0}=0.2$, the value of $\alpha=0.1$ is equivalent to that proposed by Kawabe \& Kamae (2008), $\alpha=0.2$ is equivalent to the value proposed by Horikawa et al. (2003), and $\alpha=0.3$ is equivalent to the value proposed by Iwaki \& Iwata (2011).

These previous studies used ground motion records with shorter lengths than this study because of the availability of triggered records. Furthermore, the seismic moments of these other events were smaller than that of the 2013 Awaji Island earthquake, which affects the efficiency of excitation of long-period ground motions inside the sedimentary basin. Nevertheless, the optimum value of $\alpha$ determined in this study is in accordance with some previous studies and disagrees with some others.

In this paper, we searched the best estimate of $Q$ factor as a function of $S$-wave velocity using the attenuation model in the FDM simulation by the method proposed by Graves (1996) to succeed the previous works conducted in the Osaka basin. With regard to numerical implementation of inelastic attenuation model, there were many other techniques, which have not been tested in this study, including frequency-independent or constant $Q$ models (e.g. Blanch et al.
1995; Day \& Bradley 2001; Kristek \& Moczo 2003). Therefore, the result of this study might be just an approximation of true attenuation characteristics in the Osaka basin, but, it could practically be a good approximation as far as we focus on a limited frequency range, considering its simple implementation. Of course, more thorough study on attenuation characteristics in the sedimentary basin will be expected in the future studies.

\subsection{Prominent later phase in the Osaka Plain}

As introduced in Section 3.5, the synthetic pSv in the period range 5-7 s were rather underestimated in the central part of the Osaka Plain. To elucidate this problem, the velocity waveforms for the stations within this area are plotted in Fig. 12. The waveforms were bandpass filtered at the frequency range $0.1-0.2 \mathrm{~Hz}$ (period range $5-10 \mathrm{~s}$ ). The prominent later phase propagating from southwest to northeast is indicated by the arrows. It can be seen that without exception, this later phase that arrives approximately $2 \mathrm{~min}$ after the arrival of the $S$ waves and propagates very slowly, is not reproduced by the simulation.

The horizontal particle motions of this prominent later phase at each station are plotted in Fig. 13. This prominent later phase is dominant only in the area west of the active Uemachi Fault system, which is a Quaternary reverse fault system, the western side of which is the footwall side with relatively deep bedrock. This suggests that the precise bedrock topography formed by the fault's activity is an important factor that controls the amplification of the ground 

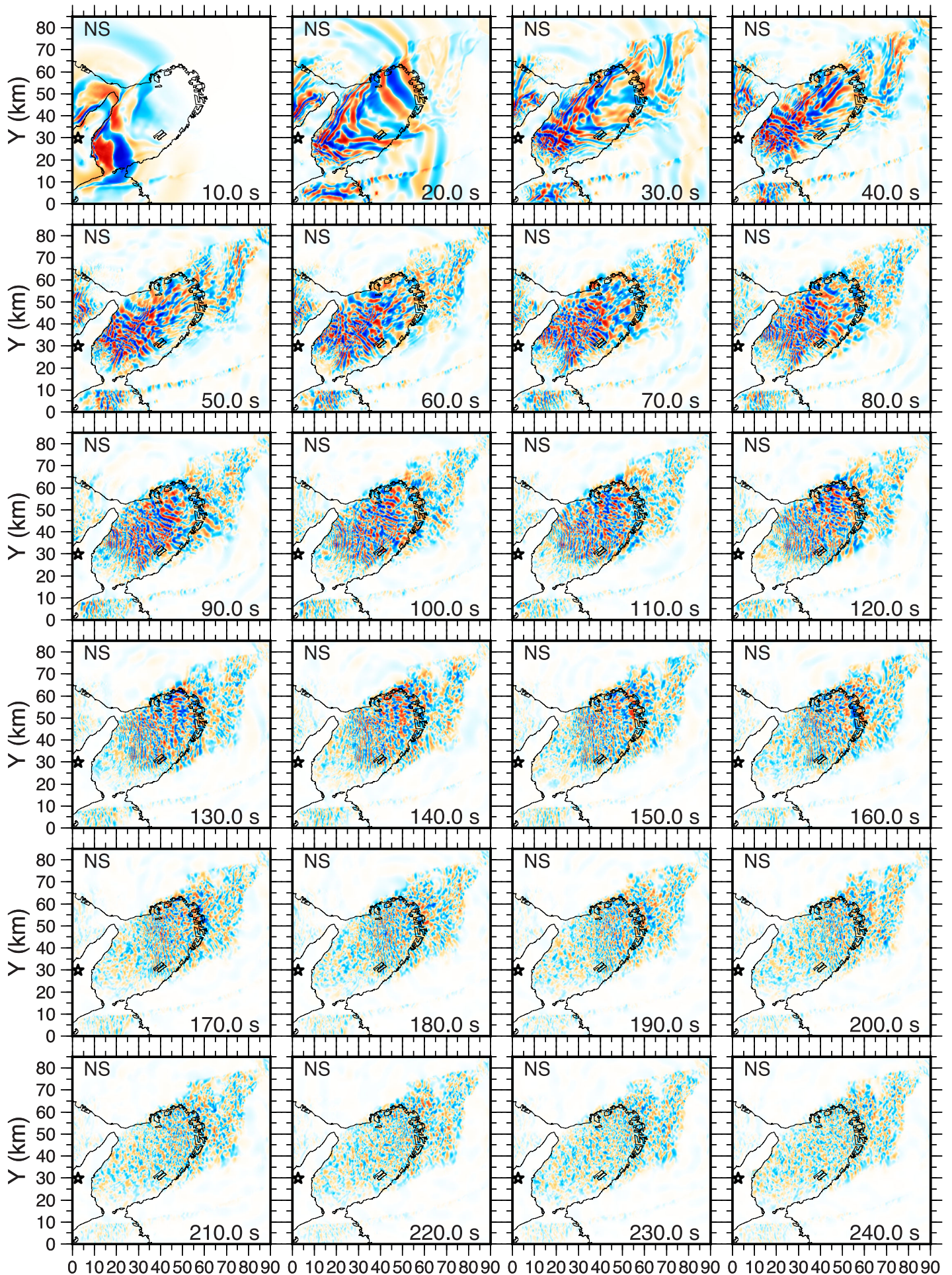

$\mathrm{X}(\mathrm{km})$

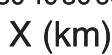

$X(\mathrm{~km})$

$X(\mathrm{~km})$

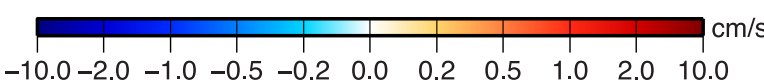

Figure 11. Snapshots of seismic wave propagation at a time step of $10 \mathrm{~s}$. N-S components are shown. Open star indicates the epicentre of the 2013 Awaji Island earthquake.

motions (e.g. Kawase 1996). The horizontal particle motions show that the NNW-SSE motion dominates this later phase.

Multiple filter analysis (Dziewonski et al. 1971) was conducted to investigate the dispersion characteristics. Fig. 14 shows the results of the dispersion analysis at OSKP50. The prominent later phase of interest is a dispersive wave, which based on the evidence presented here, is presumed to have characteristics of a Love wave propagating inside the basin. 


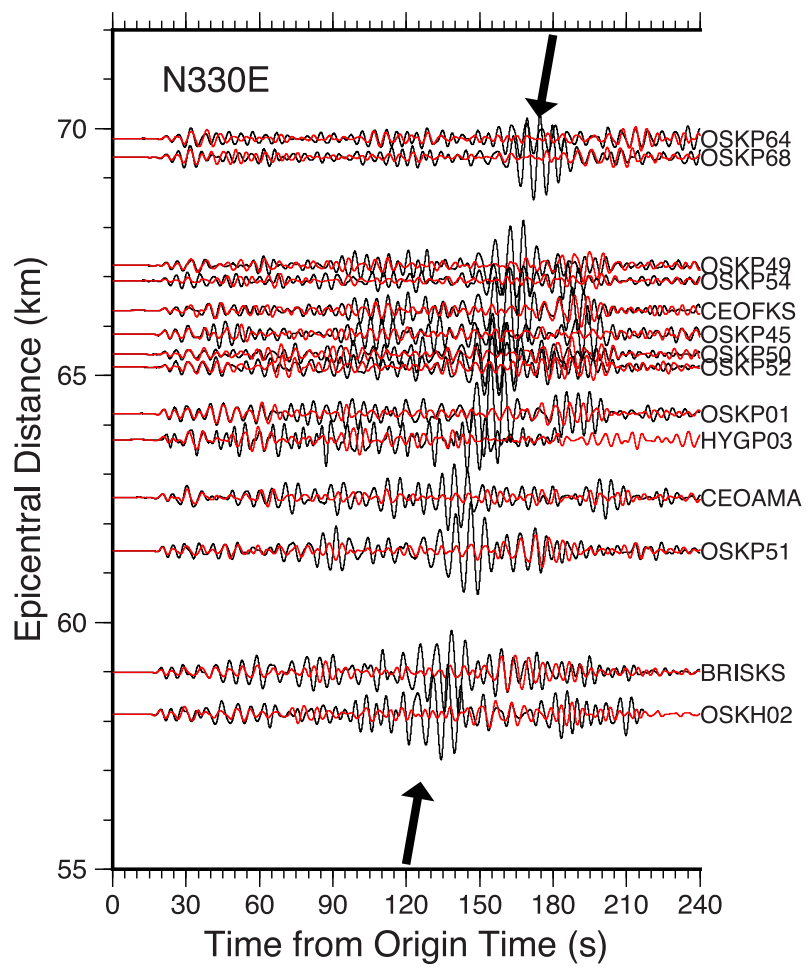

Figure 12. Comparison of the observed velocity waveforms (black) and simulated velocity waveforms (red) in the Osaka Plain according to epicentral distance. The waveforms were bandpass filtered at $0.1-0.2 \mathrm{~Hz}$. The $\mathrm{N} 330 \mathrm{E}$ component is shown. The arrows indicate the prominent later phase which is discussed in the Section 4.2 .
We estimated the direction of the origin of this later phase using semblance analysis (Neidell \& Tanar 1971) and velocity waveforms in the frequency range $0.15-0.17 \mathrm{~Hz}$ for six stations, which are indicated on the map in Fig. 15. The waveforms are rotated $30^{\circ}$ anticlockwise to obtain the waveform along N150E-N330E, which corresponds to the dominant direction of the particle motions shown in Fig. 13. The length of an individual time window is $14 \mathrm{~s}$, which is about twice the reciprocal of the central frequency. The phase velocity, backazimuth and semblance value for each time window are shown in the lower panels of Fig. 15. The estimated back azimuth corresponding to the prominent later phase is approximately $-120^{\circ}$. Therefore, this prominent later phase is thought to be dominated in the SH-type motion propagating from the southwest to northeast. Its phase velocity is approximately $1.5-2.1 \mathrm{~km} \mathrm{~s}^{-1}$, which is close to the fundamental Love wave phase velocity in this area. The group velocity of the fundamental Love wave is expected to be about $0.3 \mathrm{~km} \mathrm{~s}^{-1}$ at this frequency range (Fig. 16). These dispersion curves were calculated for the 1-D velocity structure model just beneath OSKP50 which was extracted from the UMC2013 model. The theoretical dispersion curves for Love wave is consistent with the observations shown in Fig. 12.

Based on this discussion, we supposed that the prominent later phase, observed approximately 2 min after the direct $S$ wave in the central part of the Osaka Plain, is possibly a basin-edge induced Love wave propagating from the direction of the east coast of Awaji Island, which is generated at the basin-edge of the Osaka sedimentary basin along the east coast of Awaji Island. The simulated waveform at P_UKBO (Fig. 9), which is located at an offshore airport (Kobe airport) in the Osaka bay between Awaji Island and the Osaka plain, looks reasonable, along with other inland stations between Kobe and Osaka (e.g. CEOMOT and JMA583). Many other distant stations located in the east part of the Osaka basin such as

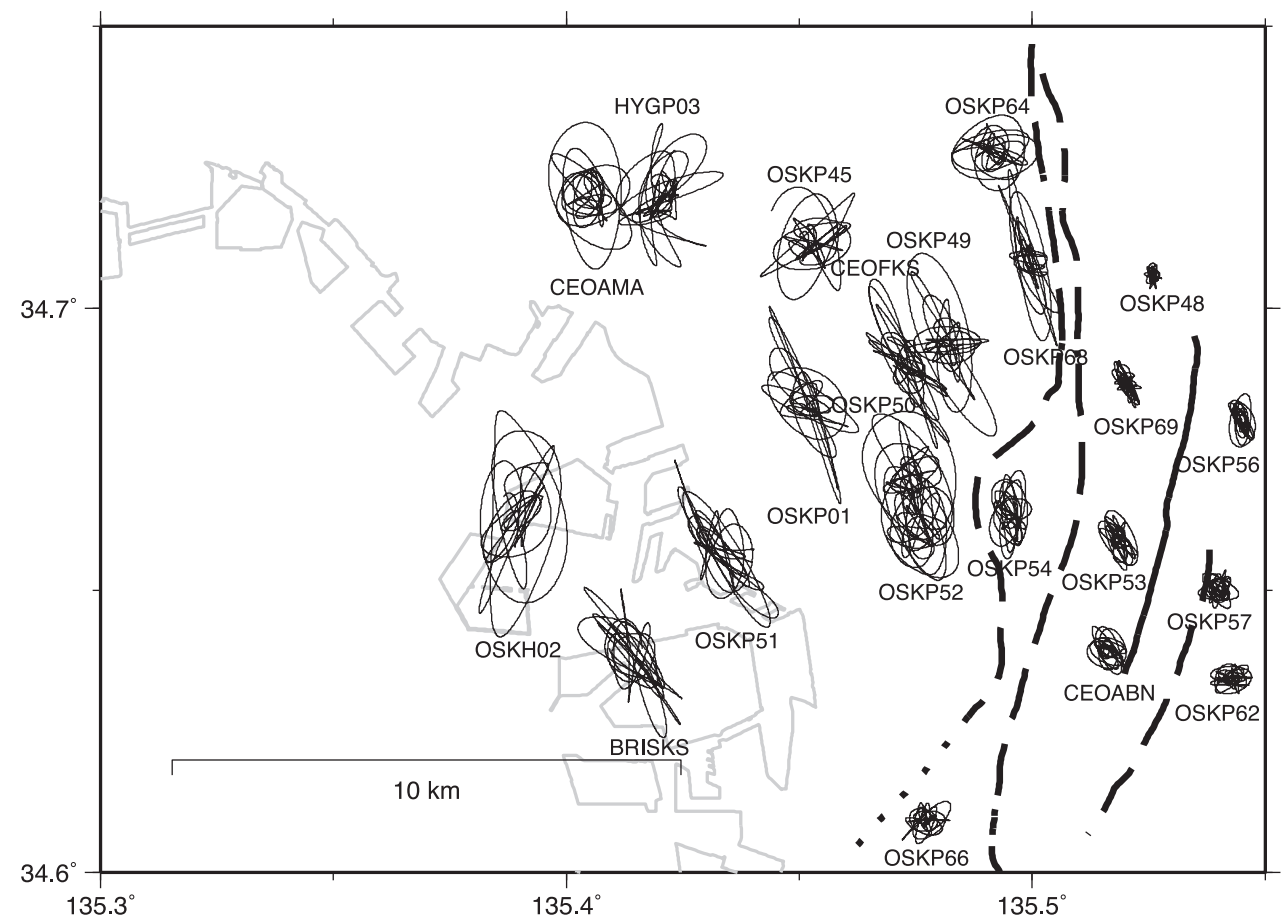

Figure 13. Horizontal particle motions of observed prominent later phase in the Osaka Plain. Broken lines represent surface fault traces of the active Uemachi Fault system (Kondo et al. 2015). 


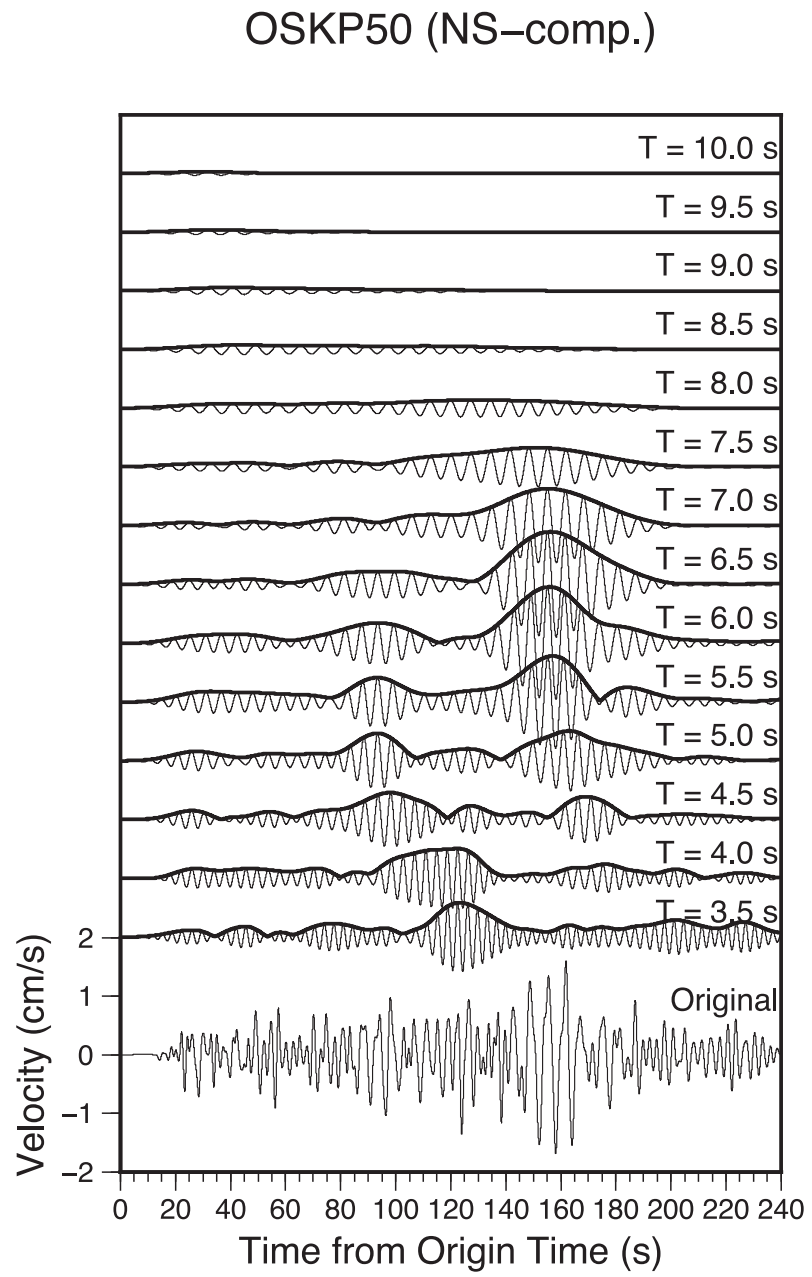

Figure 14. Dispersion characteristics of the prominent later phase at OSKP50 obtained by the multiple filter analysis (Dziewonski et al. 1971).

OSKP18, OSKP67, OSKP24 and OSKP31 also show good results (Fig. 9). The hypothesis for the failure to obtain the prominent later phase seen at the stations in the central part of the Osaka plain is that this later phase is not guided well from the sea area to the land area in the simulation. This is likely because of inadequate modelling of the bedrock geometry beneath Osaka Bay, which lies between Awaji Island and the Osaka Plain and in particular, the northeastern portion of the bay, as expected from the simulated surface wave propagation presented in the snapshots of Fig. 11. We think that an improvement of the velocity structure model beneath the sea is necessary to increase the accuracy of ground motion prediction from sources across Osaka Bay.

An alternative possibility is the effect of seawater, which was not considered in this FDM simulation. Some observational and numerical studies have investigated the effects of the seawater layer on seismic wave propagation (e.g. Nakanishi 1992; Hatayama 2004; Iida \& Hatayama 2007; Petukhin et al. 2010; Nakamura et al. 2012; Noguchi et al. 2013). These studies have shown that the water layer in deep seas, such as the Japan Trench and Nankai Trough in the Pacific Ocean, has considerable effect on the generation and propagation of Rayleigh waves. The greatest sea depth inside Osaka Bay is approximately $80 \mathrm{~m}$ (see Fig. 15) and most of the water layer is shallower than $50 \mathrm{~m}$. According to earlier studies that have focused on shallow water layers (Hatayama 2004; Iida \& Hatayama 2007), a water layer with depth $<50 \mathrm{~m}$ has little influence at frequencies
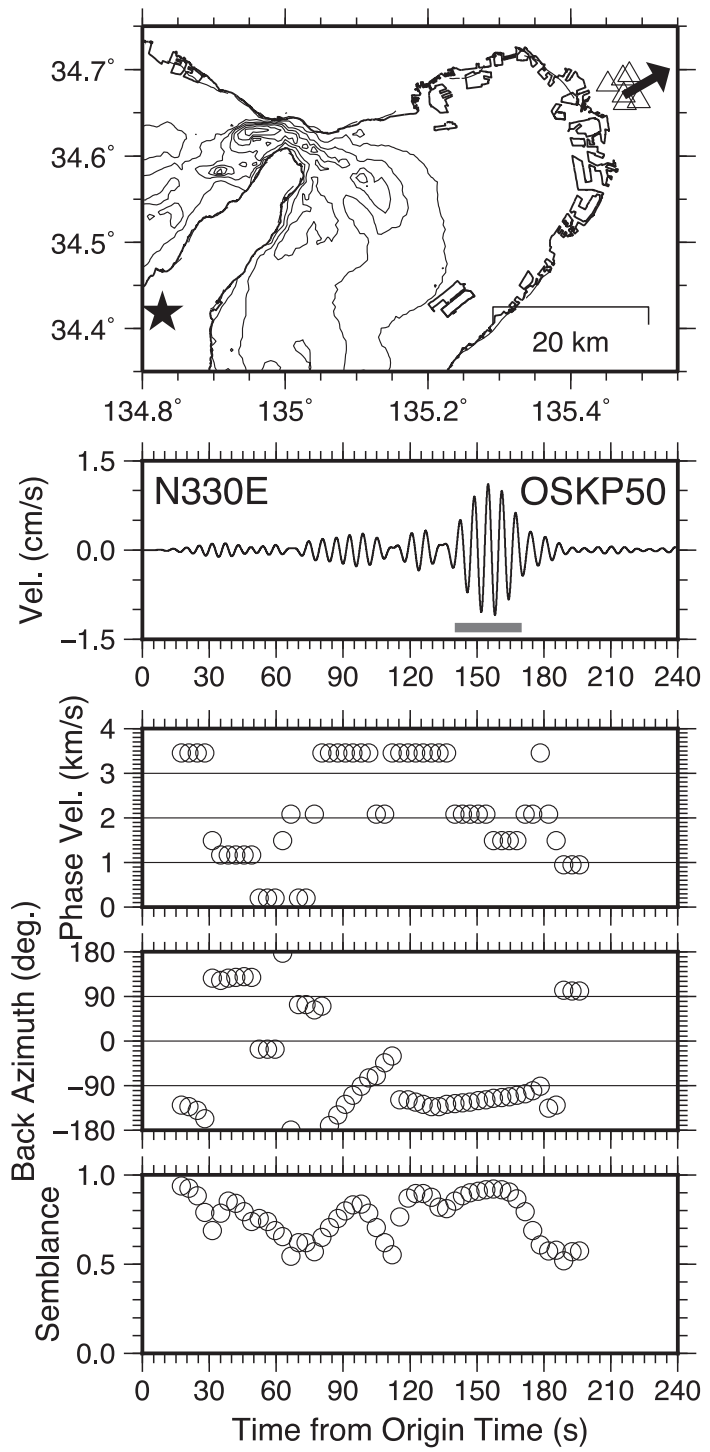

Figure 15. Top panel: map showing the strong motion stations used for the semblance analysis. Solid star indicates the epicentre of the 2013 Awaji Island earthquake. Black arrow shows the direction of the prominent later phase estimated by the semblance analysis. Contours show sea depth with 20-m intervals. Middle panel: observed velocity waveform of N330E component in $0.15-0.17 \mathrm{~Hz}$ at OSKP50. Prominent later phase is indicated by horizontal bar. Bottom panel: results of the semblance analysis: phase velocity, back azimuth and semblance value are presented in separate panels.

$<2.5 \mathrm{~Hz}$. Therefore, the seawater in Osaka Bay would not affect our simulation within the target frequency range of this paper, which is why we did not include seawater in our 3-D velocity structure model.

\section{CONCLUSIONS}

A 3-D ground motion simulation $(0.05-0.5 \mathrm{~Hz})$ of the 2013 Awaji Island earthquake in and around the Osaka sedimentary basin was conducted using the FDM with our latest 3-D basin velocity structure model of the Osaka Basin. The simulated velocity waveforms at 152 strong motion stations in and around the Osaka Basin were compared with the observed waveforms. An appropriate setting of the $Q$-factor for the sedimentary layers, when the attenuation effect was implemented using the method of Graves (1996), was deter- 

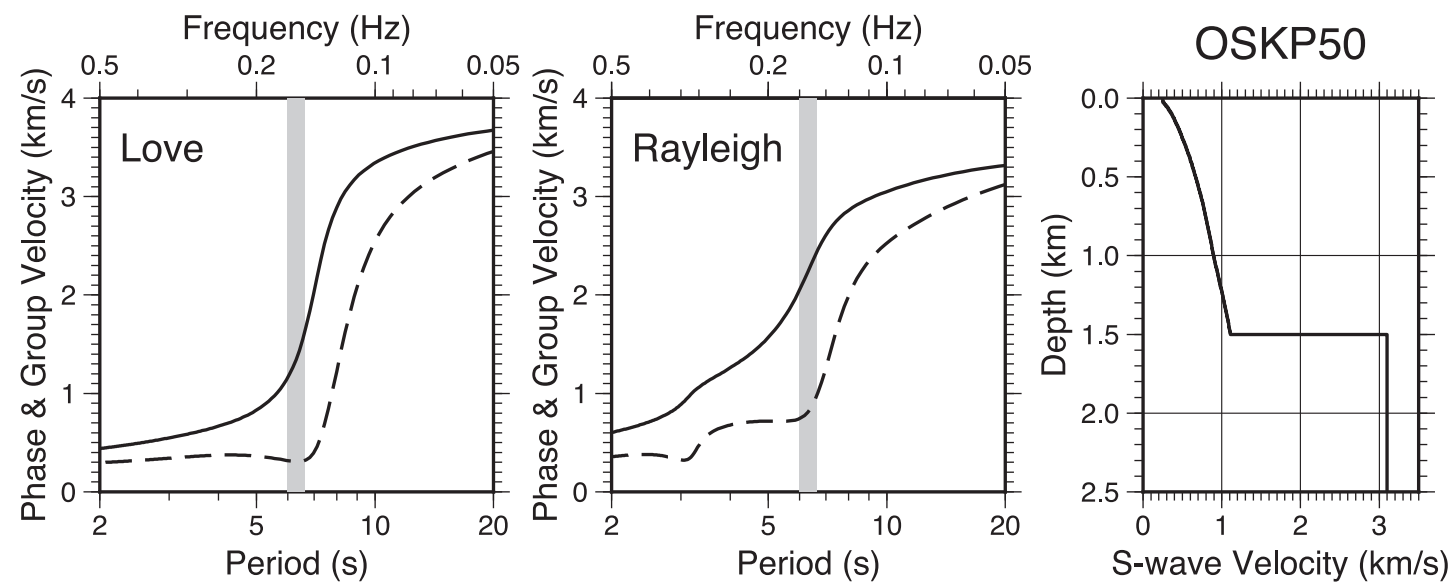

Figure 16. Theoretical dispersion curves of phase velocity (solid line) and group velocity (broken line) for the fundamental mode of Love and Rayleigh waves calculated using the 1-D velocity structure model at the station OSKP50.

mined based on the comparison of envelope shapes between the observed and simulated waveforms for the stations inside the basin. We found that $Q_{0}=0.3 V_{\mathrm{S}}$ when the reference frequency was fixed at $0.2 \mathrm{~Hz}$. This finding is consistent with that of some previous studies of the Osaka Basin. The result of this paper is thought more reliable because we used a large number of long-duration waveform records and the event occurred just within the boundary area of the Osaka Basin.

For most stations, the simulated velocity waveforms in the range $0.05-0.5 \mathrm{~Hz}$ explained the observed waveforms reasonably well in terms of both amplitude and ground motion duration. In particular, during the first $60 \mathrm{~s}$ for the direct $P$ - and $S$-wave arrivals, the amplitude and phase of the simulated waveforms matched the observed waveforms reasonably well at most stations within the Osaka Basin. The performance of the present 3-D basin velocity structure model was established as acceptable for the land area. However, some stations located outside the basin and close to the ArimaTakatsuki Tectonic Line showed relatively poor agreement, suggesting that the local subsurface structure model should be improved. In addition, a prominent later phase observed about 2 min after the $S$-wave arrival in the area of the central part of the Osaka Plain, which is located between Osaka Bay and the active Uemachi Fault system where the bedrock depth is relatively deep compared with other land areas within the basin, was not reproduced well in our FDM simulation and it caused a mismatch in the $\mathrm{pSv}$ in the period range 5-7 s. Based on the particle motions, dispersion characteristics and semblance analysis for the observed record in this area, we concluded that this later phase or late wave packet was a Love wave originating from the basin-edge in the neighbourhood of the east coast of Awaji Island. These analyses of the observed waveforms suggest that the simulated basin-edge induced Love wave is not guided well to the land area because the bedrock geometry beneath Osaka Bay, where the Love wave passed through, is poorly known. Future improvement of the velocity structure model beneath the bay is necessary to increase the accuracy of ground motion prediction within this area.

\section{ACKNOWLEDGEMENTS}

The strong motion data were provided from the K-NET and KiKnet operated by the National Research Institute for Earth Science and Disaster Prevention (NIED), Japan Meteorological Agency (JMA), Osaka Prefectural Government, Hyogo Prefectural Govern- ment, Kyoto Prefectural Government, Kyoto City Fire Department, Wakayama Prefectural Government, Nara Prefectural Government, the Committee of Earthquake Observation and Research in the Kansai Area (CEORKA), Building Research Institute (BRI), Port and Airport Research Institute (PARI) and Disaster Prevention Research Institute of Kyoto University (DPRI). In this work, we used a supercomputer at the Academic Center for Computing and Media Studies of Kyoto University. We also used Generic Mapping Tools (Wessel \& Smith 1998) to draw the figures. The digital elevation models ETOPO2v2 released by the National Geophysical Data Center (NGDC) of the National Oceanic and Atmospheric Administration (NOAA), U.S. Department of Commerce and SRTM 90-m Digital Elevation Data processed by the International Center of Tropical Agriculture (CIAT-CSI) were used to plot the surface topography. The velocity structure model used in this paper is the outcome of the Comprehensive Research on the Uemachi Fault Zone founded by the Ministry of Education, Culture, Sports, Science, and Technology (MEXT), Japan. We thank the Editor Frank Krüger, Florent De Martin and an anonymous reviewer for critical and insightful comments. This work was partially supported by the Earthquake and Volcano Hazards Observation and Research Program of MEXT and by the Grant-in-Aid for Scientific Research (B) 23310121 and Grant-in-Aid for Young Scientists (B) 25750146 from the Japan Society for the Promotion of Science (JSPS).

\section{REFERENCES}

Aagaard, B.T. et al., 2008. Ground-motion modeling of the 1906 San Francisco earthquake. Part I: Validation using the 1989 Loma Prieta earthquake, Bull. seism. Soc. Am., 98, 989-1011.

Aoi, S. \& Fujiwara, H., 1999. 3D finite-difference method using discontinuous girds, Bull. seism. Soc. Am., 89, 918-930.

Aoi, S., Honda, R., Morikawa, N., Sekiguchi, H., Suzuki, H., Hayakawa, Y., Kunugi, T. \& Fujiwara, H., 2008. Three-dimensional finite difference simulation of long-period ground motions for the 2003 Tokachi-oki, Japan, earthquake, J. geophys. Res., 113, B07302, doi:10.1029/2007JB005452.

Aoi, S., Kunugi, T., Nakamura, H. \& Fujiwara, H., 2011. Deployment of new strong motion seismographs of K-NET and KiK-net, in Earthquake Data in Engineering Seismology, pp. 167-186, eds Akkar, S., Gülkan, P. \& van Eck, T., Springer.

Bard, P.-Y. \& Bouchon, M., 1980a. The seismic response of sediment-filled valleys. Part 1. The case of incident $\mathrm{SH}$ waves, Bull. seism. Soc. Am., 70, $1263-1286$ 
Bard, P.-Y. \& Bouchon, M., 1980b. The seismic response of sediment-filled valleys. Part 2. The case of incident P-SV waves, Bull. seism. Soc. Am., 70, 1921-1941.

Bielak, J. et al., 2010. The ShakeOut earthquake scenario: verification of three simulation sets, Geophys. J. Int., 180, 375-404.

Blanch, J.O., Robertsson, J.O.A. \& Symes, W.W., 1995. Modeling of a constant Q: methodology and algorithm for an efficient and optimally inexpensive viscoelastic technique, Geophysics, 60, 176-184.

Day, S.M. \& Bradley, C.R., 2001. Memory-efficient simulation of anelastic wave propagation, Bull. seism. Soc. Am., 91, 520-531.

Day, S.M., Bielak, J., Dreger, D., Graves, R., Larsen, S., Olsen, K.B. \& Pitarka, A, 2001. Tests of 3D elastodynamic codes. Final report for Lifelines Project 1A01, Pacific Earthquake Engineering Research Center, $24 \mathrm{pp}$.

Day, S.M., Bielak, J., Dreger, D., Graves, R., Larsen, S., Olsen, K.B. \& Pitarka, A., 2003. Tests of 3D elastodynamic codes. Final report for Lifelines Project 1A02, Pacific Earthquake Engineering Research Center, $32 \mathrm{pp}$.

Dhakal, Y. \& Yamanaka, H., 2013. An evaluation of 3-D velocity models of the Kanto basin for long-period ground motion simulations, J. Seism., 17, 1073-1102.

Dziewonski, A., Bloch, S. \& Landisman, M., 1971. A technique for the analysis of transient seismic signals, Bull. seism. Soc. Am., 61, 343-356.

Frankel, A., 1993. Three-dimensional simulations of ground motions in the San Bernardino valley, California, for hypothetical earthquakes on the San Andreas fault, Bull. seism. Soc. Am., 83, 1020-1041.

Gassmann, F., 1951. Elastic waves through a packing of spheres, Geophysics, 16, 673-685.

Geological Survey of Japan, 2012. Seamless Digital Geological Map of Japan 1:200,000, July 3, 2012 version, Geological Survey of Japan, National Institute of Advanced Industrial Science and Technology.

Graves, R.W., 1996. Simulating seismic wave propagation in 3D elastic media using staggered-grid finite differences, Bull. seism. Soc. Am., 86, 1091-1106.

Graves, R.W., Pitarka, A. \& Somerville, P.G., 1998. Ground-motion amplification in the Santa Monica Area: effects of shallow basin-edge structure, Bull. seism. Soc. Am., 88, 1224-1242.

Hatayama, K., 2004. Theoretical evaluation of effects of sea on seismic ground motion, in Proceedings of the Thirteenth World Conference on Earthquake Engineering (13WCEE), Vancouver, BC, Canada, August 1-6, 2004, paper no. 3229.

Hatayama, K., Matsunami, K., Iwata, T. \& Irikura, K., 1995. Basin-induced Love waves in the eastern part of the Osaka basin, J. Phys. Earth, 43, 131-155.

Horikawa, H. et al., 2003. A three-dimensional subsurface structure model beneath the Osaka sedimentary basin, southwest Japan, with fault-related structural discontinuities, Annual Report on Active Fault and Paleoearthquake Researches, 3, 225-259 (in Japanese).

Horike, M., 1988. Analysis and simulation of seismic ground motions observed in a sedimentary basin, J. Phys. Earth, 36, 135-154.

Iida, M. \& Hatayama, K., 2007. Effects of seawater of Tokyo Bay on shortperiod strong ground motion, Bull. seism. Soc. Am., 97, 1324-1333.

Itihara, M., Yoshikawa, S. \& Kamei, T., 1997. The Pliocene-Pleistocene boundary in Japan: the Osaka Group, Kinki district, in The Pleistocene Boundary and Beginning of the Quaternary, pp. 239-243, ed. Van Couvering, J.A., Cambridge Univ. Press.

Itoh, Y., Takemura, K., Ishiyama, T., Tanaka, Y. \& Iwaki, H., 2000. Basin formation at a contractional bend of a large transcurrent fault: PlioPleistocene subsidence of the Kobe and northern Osaka Basins, Japan, Tectonophysics, 321, 327-341.

Iwaki, A. \& Iwata, T., 2010. Simulation of long-period ground motion in the Osaka sedimentary basin: performance estimation and the basin structure effects, Geophys. J. Int., 181, 1062-1076.

Iwaki, A. \& Iwata, T., 2011. Estimation of three-dimensional boundary shape of the Osaka sedimentary basin by waveform inversion, Geophys. J. Int., 186, 1255-1278

Iwata, T., Kagawa, T., Petukhin, A. \& Ohnishi, Y., 2008. Basin and crustal velocity structure models for the simulation of strong ground motions in the Kinki area, Japan, J. Seism., 12, 223-234.
Jarvis, A., Reuter, H.I., Nelson, A. \& Guevara, E., 2008. Hole-filled seamless SRTM data V4, International Centre for Tropical Agriculture (CIAT) Available at: http://srtm.csi.cgiar.org, last accessed December 2014.

Joyner, W.B., 2000. Strong motion from surface waves in deep sedimentary basins, Bull. seism. Soc. Am., 90, S95-S112.

Kagawa, T., Sawada, S., Iwasaki, Y. \& Emi, S., 1990. Underground velocity structure of Osaka Basin based upon explosion refraction data, Zisin $2 \mathrm{~J}$ seism. Soc. Jpn., 43, 527-537 (in Japanese with English abstract).

Kagawa, T., Sawada, S., Iwasaki, Y. \& Nanjo, J., 1993. Modeling the deep sedimentary structure in the Osaka basin, in Proceedings of the 22nd JSCE Earthquake Engineering Symposium, Kyoto, Japan, July 1993, pp. 199-202 (in Japanese).

Kagawa, T., Iemura, H., Irikura, K. \& Toki, K., 2004a. Strong ground motion observation by the Committee of Earthquake Observation and Research in the Kansai Area (CEORKA), J. Jpn. Assoc. Earthq. Eng., 4(3) 128-133.

Kagawa, T., Zhao, B., Miyakoshi, K. \& Irikura, K., 2004b. Modeling of 3D basin structures for seismic wave simulations based on available information on the target area: case study of the Osaka basin, Bull. seism. Soc. Am., 94, 1353-1368.

Kashima, T., 2004. Strong motion network operated by Building Research Institute, J. Jpn. Assoc. Earthq. Eng., 4(3), 84-89.

Katao, H. et al., 2014. Focal mechanisms of aftershocks for the M6.3 Awaji Island earthquake on APR. 13, 2013, Ann. Disas. Prev. Res. Inst., Kyoto Univ., 57B, 80-84 (in Japanese with English abstract).

Kawabe, H. \& Kamae, K., 2008. Prediction of long-period ground motions from huge subduction earthquakes in Osaka, Japan, J. Seism., 12, 173184.

Kawase, H., 1996. The cause of the damage belt in Kobe: "the basin-edge effect," constructive interference of the direct S-wave with the basin induced diffracted/Rayleigh waves, Seism. Res. Lett., 67(5), 25-34.

Kawase, H. \& Aki, K., 1989. A study on the response of a soft basin for incident S, P, and Rayleigh waves with special reference to the long duration observed in Mexico City, Bull. seism. Soc. Am., 79, 1361-1382.

Koketsu, K. \& Kikuchi, M., 2000. Propagation of seismic ground motion in the Kanto basin, Japan, Science, 288, 1237-1239.

Kondo, H., Sugito, N., Yoshioka, T., Tsutsumi, H. \& Kimura, H., 2015. Revisited spatial distribution of the Uemachi fault zone, Osaka, revealed by digital elevation models, Active Fault Res., 42, 1-34 (in Japanese with English abstract).

Kristek, J. \& Moczo, P., 2003. Seismic-wave propagation in viscoelastic media with material discontinuities: a 3D forth-order staggered-grid finitedifference modeling, Bull. seism. Soc. Am., 93, 2273-2280.

Levander, A.R., 1988. Fourth-order finite-difference P-SV seismograms, Geophysics, 53, 1425-1436.

Ma, S., Prieto, G.A. \& Beroza, G.C., 2008. Testing community velocity models for southern California using the ambient seismic field, Bull. seism. Soc. Am., 98, 2694-2714.

Maeda, N. \& Watanabe, H., 1984. Mode of activity of microearthquakes in the case of the middle and northern parts of Kinki district, southwestern Japan, Zisin2 J. seism. Soc. Jpn., 37, 579-598 (in Japanese with English abstract).

Matsuzawa, T., Takeda, T., Matsubara, M. \& Kimura, H., 2013. The earthquake in the Awajishima Island region on April 13, 2013, Rep. Coord. Comm. Earthq. Pred., 90, 356-361 (in Japanese).

Maufroy, E. et al., 2015. Earthquake ground motion in the Mygdonian basin, Greece: the E2VP verification and validation of 3D numerical simulation up to $4 \mathrm{~Hz}$, Bull. seism. Soc. Am., 105, 1398-1418.

Meza-Fajardo, K.C. \& Papageorgiou, A.S., 2008. A nonconvolutional, splitfield, perfectly matched layer for wave propagation in isotropic and anisotropic elastic media: Stability analysis, Bull. seism. Soc. Am., 98, $1811-1836$

Miyakoshi, K., Kagawa, T., Sawada, S., Echigo, T. \& Horie, Y., 1997. Modeling the deep sedimentary structure in the Osaka basin (2), in Proceedings of the 24th JSCE Earthquake Engineering Symposium, Kobe, Japan, July 24-26, 1997, pp. 33-36 (in Japanese)

Miyakoshi, K., Kagawa, T., Zhao, B., Tokubayashi, M. \& Sawada, S., 1999. Modeling the deep sedimentary structure in the Osaka basin (3), in Proceedings of the 25th JSCE Earthquake Engineering Symposium, Tokyo, Japan, July 29-31, 1999, pp. 185-188 (in Japanese). 
Moczo, P., Kristek, J., Vavryčuk, V, Archuleta, R.J. \& Halada, L., 2002. 3D heterogeneous staggered-grid finite-difference modeling of seismic motion with volume harmonic and arithmetic averaging of elastic moduli and densities, Bull. seism. Soc. Am., 92, 3042-3066.

Moczo, P., Kristek, J., Galis, M., Chaljub, E. \& Etienne, V., 2011. 3-D finite difference, finite-element, didcontinuous-Galerkin and spectral-element schemes analysed for their accuracy with respect to $P$-wave to $S$-wave speed ratio, Geophys. J. Int., 187, 1645-1667.

Moczo, P., Kristek, J. \& Galis, M., 2014. The Finite-Difference Modelling of Earthquake Motions: Waves and Ruptures, Cambridge Univ. Press, $365 \mathrm{pp}$.

Morikawa, N., Senna, S., Hayakawa, Y. \& Fujiwata, H., 2011. Shaking maps for scenario earthquakes by applying the upgraded version of the strong ground motion prediction method "recipe", Pure appl. Geophys., 168, 645-657.

Nakagawa, K., Shiono, K., Inoue, K. \& Sano, M., 1996. Geological characteristics and problems in and around Osaka basin as a basis for assessment of seismic hazards, Soils Foundat., 36 (special issue), 15-28.

Nakamura, T., Takenaka, H., Okamoto, T. \& Kaneda, Y., 2012. FDM simulation of seismic-wave propagation for an aftershock of the 2009 Suruga Bay earthquake: effects of ocean-bottom topography and seawater layer, Bull. seism. Soc. Am., 102, 2420-2435.

Nakanishi, I., 1992. Rayleigh waves guided by sea-trench topography, Geophys. Res. Lett., 19, 2385-2388.

National Institute of Advanced Industrial Science and Technology (AIST), 2007. Active Fault Database of Japan, December 13, 2007 version, Research Information Database DB095, National Institute of Advanced Industrial Science and Technology. Available at: https:// gbank.gsj.jp/activefault/index_e_gmap.html, last accessed June 2010.

Neidell, S.N. \& Taner, M.T., 1971. Semblance and other coherency measures for multichannel data, Geophysics, 36, 482-497.

Nishimae, Y., 2004. Observation of seismic intensity and strong ground motion by Japan Meteorological Agency and local governments in Japan, J. Jpn. Assoc. Earthq. Eng., 4(3), 75-78.

Noguchi, S., Maeda, T. \& Furumura, T., 2013. FDM simulation of an anomalous later phase from the Japan Trench subduction zone earthquakes, Pure appl. Geophys., 170, 95-108.

Nozu, A., 2004. Current status of strong-motion earthquake observation in Japanese ports, J. Jpn. Assoc. Earthq. Eng., 4(3), 79-83.

Olsen, K.B., Day, S.M. \& Bradley, C.R., 2003. Estimation of Q for longperiod $(>2 \mathrm{sec}$ ) waves in the Los Angeles basin, Bull. seism. Soc. Am., 93, 627-638.

Petukhin, A., Iwata, T. \& Kagawa, T., 2010. Study on the effect of the oceanic water layer on strong ground motion simulations, Earth Planets Space, 62, 621-630.

Pitarka, A., 1999. 3D elastic finite-difference modeling of seismic motion using staggered grids with non-uniform spacing, Bull. seism. Soc. Am., 89, 54-68

Pitarka, A., Irikura, K., Iwata, K. \& Sekiguchi, H., 1998. Three-dimensional simulation of the near-fault ground motion for the 1995 Hyogo-ken Nanbu (Kobe), Japan, earthquake, Bull. seism. Soc. Am., 88, 428-440.

Pitarka, A., Graves, R. \& Somerville, P., 2004. Validation of a 3D velocity model of the Puget Sound Region based on modeling ground motion from the 28 February 2001 Nisqually earthquake, Bull. seism. Soc. Am., 94, $1670-1689$

Sekiguchi, H., Yoshimi, M., Horikawa, H., Yoshida, K., Kunimatsu, S. \& Satake, K., 2008. Prediction of ground motion in the Osaka sedimentary basin associated with the hypothetical Nankai earthquake, J. Seism., 12, 185-195.

Sekiguchi, H., Yoshimi, M., Asano, K., Horikawa, H., Saomoto, H., Hayashida, T. \& Iwata, T., 2013. Newly developed 3D velocity structure model of the Osaka sedimentary basin, in Abstracts of Japan Geoscience Union Meeting, Chiba, Japan, May 19-24, 2013, SSS33-P01.

Uebayashi, H., Kawabe, H. \& Kamae, K., 2012. Reproduction of microseism $\mathrm{H} / \mathrm{V}$ spectral features using a three-dimensional complex topographical model of the sediment-bedrock interface in the Osaka sedimentary basin, Geophys. J. Int., 189, 1060-1074.
U.S. Department of Commerce, National Oceanic and Atmospheric Administration, National Geophysical Data Center, 2006. 2-minute Gridded Global Relief Data (ETOPO2v2). Available at: http://www.ngdc.noaa.gov/mgg/fliers/06mgg01.html, last accessed August 2014.

Virieux, J., 1986. P-SV wave propagation in heterogeneous media: velocitystress finite-difference method, Geophysics, 51, 889-901.

Wessel, P. \& Smith, W.H.F., 1998. New, improved version of Generic Mapping Tools released, EOS, Trans. Am. geophys. Un., 79, 579.

Yamada, K. \& Horike, M., 2007. Inference of $Q$-values below $1 \mathrm{~Hz}$ from borehole and surface data in the Osaka basin by three-component waveform fitting, Bull. seism. Soc. Am., 97, 1267-1278.

Yomogida, K. \& Etgen, J.T., 1993. 3-D wave propagation in the Los Angeles Basin for the Whittier-Narrows earthquake, Bull. seism. Soc. Am., 83, $1325-1344$.

Yoshimura, C. et al., 2012. Benchmark tests for strong ground motion prediction methods using numerical methods, in Proceedings of the 15th World Conference on Earthquake Engineering (15WCEE), Lisbon, Portugal, September 24-28, 2012, paper no. 562.

Zeng, C., Zia, J., Miller, R.D. \& Tsoflias, G.P., 2011. Application of the multiaxial perfectly matched layer (M-PML) to near-surface seismic modeling with Rayleigh waves, Geophysics, 76, T43-T52.

\section{SUPPORTING INFORMATION}

Additional Supporting Information may be found in the online version of this paper:

Figure S1. Comparisons of synthetic waveforms between FDM (red) and DW (black).

Figure S2. Comparisons of synthetic waveforms between FDM (red) and DW (black).

Figure S3. Comparisons of synthetic waveforms between FDM (red) and DW (black).

Figure S4. Comparisons of the observed velocity waveforms (black) and simulated velocity waveforms for different dip angles. The leftand right-hand columns show the waveforms of the N-S and E-W components, respectively. The waveforms were bandpass filtered between $0.05 \mathrm{~Hz}$ and $0.5 \mathrm{~Hz}$. Two components are plotted on the same scale and normalized by the maximum observed amplitude for each station. The numbers above the waveforms are the maximum amplitude of the observed waveforms in $\mathrm{cm} \mathrm{s}^{-1}$. Red, dip $=65^{\circ}$ (original); green, $\operatorname{dip}=55^{\circ}$; blue, $\operatorname{dip}=75^{\circ}$.

Figure S5. Comparisons of the observed velocity waveforms (black) and simulated velocity waveforms (red). The left-hand, middle and right-hand columns show the waveforms of the N-S, E-W and updown components, respectively. The waveforms were bandpass filtered at $0.05-0.5 \mathrm{~Hz}$. Three components are plotted on the same scale and normalized by the maximum observed amplitude for each station. The numbers above the waveforms are the maximum amplitude of the observed waveforms in $\mathrm{cm} \mathrm{s}^{-1}$. See Fig. 4 for the locations of each strong motion station. The stations are ordered by epicentral distance.

Table S1. Material parameters of WP2_LOH3 model.

Table S2. Coordinates of receivers.

Table S3. Material parameters of E2VP_CAN2 model.

Table S4. Material parameters of E2VP_CAN3 model.

Table S5. Focal mechanisms of three models tested (http://gji. oxfordjournals.org/lookup/suppl/doi:10.1093/gji/ggv543/-/DC1).

Please note: Oxford University Press is not responsible for the content or functionality of any supporting materials supplied by the authors. Any queries (other than missing material) should be directed to the corresponding author for the paper. 